Christian Jaser

\title{
Infamis etiam campio non esse potest. Kämpen in deutschen und italienischen Städten des Spätmittelalters zwischen Marginalität und Rechtspflege
}

\begin{abstract}
Historical research on the complex legal and social roles of medieval mercenary champions hired as proxies to fight in judicial duels has long been dominated by simplistic categorisations and static repetitions of their reputed infamy. Concentrating on account books and statutes of late medieval German and Italian cities, this article seeks, in contrast, to reconstruct the dynamic institutionalisation and control of civic champions. Thereby, their ambiguous perception reveals a complex interplay between marginality, enhancement of their status as legal agents and a latent suspiciousness regarding their peculiar representational role.
\end{abstract}

Keywords: champions, urban history, infamy, marginality, legal agency

DOI 10.1515/mial-2014-0021

\section{Hinführung: Der Kämpe - eine marginale Figur?}

The tribunals were stained with the blood, perhaps, of innocent and respectable citizens; the law, which now favours the rich, then yielded to the strong; and the old, the feeble, and the infirm, were condemned, either to renounce the fairest claims and possessions, to sustain the dangers of an unequal conflict, or to trust the doubtful aid of a mercenary champion. ${ }^{1}$

In diesen Worten des englischen Aufklärungshistorikers Edward Gibbon spiegelt sich ein grundsätzliches Unbehagen, das dem Prinzip der Kampfstellvertretung

1 Edward Gibbon, History of the Decline and Fall of the Roman Empire. Bd. 2. New York 1840, c. 38, S. 423.

Dr. Christian Jaser: Humboldt-Universität zu Berlin, Philosophische Fakultät I, Institut für Geschichtswissenschaften, Lehrstuhl für Mittelalterliche Geschichte II, Unter den Linden 6, 10099 Berlin, E-Mail: christian.jaser@geschichte.hu-berlin.de 
im Allgemeinen und den Lohnkämpfern im Besonderen in der historischen Forschung lange Zeit entgegengebracht wurde. Was sollte man schon mit dieser Stellvertreterfigur mit Schild und Kampfstock anfangen, die Leib und Leben für einen fremden Rechtsstandpunkt einsetzte, die einem binär codierten Wahrheitsbeweis und mithin als agonaler Entscheidungsakteur eines Gottesurteils diente, zugleich aber daraus im Wortsinne Kapital schlug und aus der tentatio Dei eine seriell praktizierte Profession machte? Hat man hierbei wirklich „reckless desperadoes" vor Augen, die nichts anderes tun mussten, als ihre alltagskriminelle Gewaltneigung in den Verfahrensgang des gerichtlichen Zweikampfes einzubringen, wie der in diesem Kontext unvermeidliche Henry Charles Lea vermutete?2 ${ }^{2}$ Oder lag Hans KunN richtig, als er die mittelalterlichen campiones oder pugiles zusammen mit den nordischen Berserkern als Epiphänomene der römischen Gladiatoren apostrophierte ${ }^{3}$ Man wird sich davor hüten müssen, das diachron ausgreifende und regional sowie phänomenologisch zu differenzierende Phänomen der Kampfstellvertreter auf einen pauschalen Nenner bringen zu wollen, noch dazu, wenn dieser von anachronistischen Vorannahmen einer linearen Rationalisierungs- und Modernisierungsperspektive gespeist ist. Das gilt in noch höherem Maße für die Frage nach der sozialen und rechtlichen Stellung dieser professionellen Zweikampfakteure, die von der Forschung häufig mit einer gewissen „Sehnsucht nach Eindeutigkeit“4 beantwortet worden ist. Lässt man sich auf die häufig zu verzeichnende Verengung auf normative und juristische Quellen ein, zeigt sich etwa diesseits und jenseits der Alpen bereits eine erhebliche Spannbreite, was den Status der Kämpen in der zeitgenössischen Rezeption anbelangt. An Deutlichkeit nichts zu wünschen übrig lässt einerseits eine Stelle aus dem Landrecht des zwischen 1220 und 1235 entstandenen ,Sach-

2 Henry Charles Lea, Superstition and Force. Essays on The Wager of Law - The Wager of Battle - The Ordeal - Torture. Philadelphia 1878, S. 165: „Reckless desperadoes, skilled at quarter-staff, or those whose familiarity with sword and dagger, gained by a life spent in ceaseless brawls, gave them confidence in their own ability, might undertake it as an occupation which exposed them to little risk beyond what they habitually incurred, and of such was the profession generally composed.“ Zu Henry Charles Lea vgl. Hans Rudolf Guggisberg, Henry Charles Lea als Geschichtsschreiber der mittelalterlichen Kirche. In: Ders., Das europäische Mittelalter im amerikanischen Geschichtsdenken des 19. und des frühen 20. Jahrhunderts (Basler Beiträge zur Geschichtswissenschaft 92). Basel, Stuttgart 1964, S. 85-101.

3 Vgl. Hans Kuhn, Kämpen und Berserker. In: Frühmittelalterliche Studien 2 (1968), S. 218-227, hier S. 227: „Die Geschichte der germanischen Kämpen und wohl auch der Berserker fängt bei den Gladiatoren an. "Vgl. dazu auch Sarah Neumann, Der gerichtliche Zweikampf: Gottesurteil Wettstreit - Ehrensache (Mittelalter-Forschungen 31). Sigmaringen 2010, S. 184, Anm. 976, und Dagmar Hüpper-Dröge, Der gerichtliche Zweikampf im Spiegel der Bezeichnungen für ,Kampf ${ }^{4}$, ,Kämpfer‘, ,Waffen‘. In: Frühmittelalterliche Studien 18 (1984), S. 607-661, hier S. 632, Anm. 156. 4 Neumann (Anm. 3), S. 21. 
senspiegel' Eikes von Repgow, die in der eher dünnen Kämpenforschung beinahe $\mathrm{zu}$ Tode zitiert worden ist: Kemphen unde ire kindere [...] de sint alle rechtelos. ${ }^{5}$ Am anderen Ende des Spektrums steht der nach 1245 verstorbene Roffredo Beneventano und seine beinahe zeitgleich entstandene, bis ins 15. Jahrhundert hinein gelesene ,Summa de pugna‘. In diesem Hauptwerk der italienischen Zweikampfliteratur des 13. Jahrhunderts wird der gerichtliche Zweikampf aus dem Blickwinkel des römischrechtlichen Zivilprozesses betrachtet, ${ }^{6}$ der in diesen Jahren die europäische Rechtskultur eroberte. Entsprechend münzte der beneventanische Jurist die militärische Metaphorisierung des Anwaltsberufs im ,Codex Justinianus‘ in eine prozessrechtliche Schlüsselstellung des Kämpen um: „Der Kämpe und der Anwalt gleichen sich, denn genauso wie der Advokat entscheidet auch der Kämpe eine untersuchte Angelegenheit. “7 Diese funktionale

5 Eike von Repgow, Sachsenspiegel. Landrecht, Buch I, c. XXXVIII, §1. In: Sachsenspiegel. Landrecht und Lehnrecht. Hrsg. v. Friedrich Ebel (Reclams Universal-Bibliothek 3355). Stuttgart 2005, S. 52. Vgl. Hans-Peter Hils, „Kempen unde er Kinder ... de sin alle rechtelos“. Zur sozialen und rechtlichen Stellung der Fechtmeister im späten Mittelalter. In: Jörg Fichte, Karl Heinz Göller u. Bernhard Schimmelpfennig (Hgg.), Zusammenhänge, Einflüsse, Wirkungen. Kongressakten zum 1. Symposium des Mediävistenverbandes in Tübingen. Berlin u. a. 1986, S. 255-271; Neumann (Anm. 3), S. 184.

6 Vgl. Giovanni da Legnano, Tractatus De Bello, De Represaliis et De Duello. Hrsg. v. Thomas Erskine Holland. Oxford 1917, lib. VI, pars 7, c. clxxxvii, S. 188: Qualiter duellum purgatorium ad instar sit iudicii contentiosi? Et hic praetermitto quod duellum est redactum ad instar iudicii contentiosi, nam sicut in iudicio contentioso sunt actor, reus, iudex, instrumenta causam instruentia, per quae, largo modo sumpta pro quibuscumque causam instruentibus, ut l. ff. De fide instrum., fit veritatis declaratio, ut feratur definitiva sententia, sic in duello sunt actor et reus, ut puta provocans et provocatus, iudex, instrumenta, utpote arma, quibus se invicem percutiunt. Nam sicut in iudicio contentioso quis alium convincit testibus, scripturis, et confessionibus, ut De restit. spol., cum ad sedem, sic in duello armis corporalibis convincit, ut sicut in primo sic convictus est, in casu condemnationis, sic a simili convictus in hoc. Ad similitudinum igitur iudicii contentiosi quaerendum est de hoc iudicio, sicilicet, duellari.

7 Roffredo Beneventano, Summa de pugna, c. V, ed. In: Federico Patetta, Le ordalie. Studio di storia del diritto e scienza del diritto comparato. Turin 1890, S. 489: Concordant enim campio et advocatus, unde sicut per advocatum causa examinata deciditur, ut C. de advo. di. iu. l. "advocati”, ita et per campionem. Falls nicht anders angegeben, stammen die Übersetzungen vom Verfasser. Vgl. Codex Justinianus, 2.7.14 (De advocatis diversorum iudiciorum). In: Corpus Iuris Civilis. Hrsg. v. Paul Krüger. 5. Aufl. Bd. 2. Berlin 1892, S. 39: Advocati, qui dirimunt ambigua fata causarum suaeque defensionis viribus in rebus saepe publicis ac privatis lapsa erigunt, fatigata reparant, non minus provident humano generi, quam si proeliis atque vulneribus patriam parentesque salvarent. nec enim solos nostro imperio militare credimus illos, qui gladiis clupeis et thoracibus nituntur, sed etiam advocatos: militant namque causarum patroni, qui gloriosae vocis confisi munimine laborantium spem vitam et posteros defendunt. Vgl. dazu auch Marco Cavina, Il duello giudiziario per punto d'onore. Genesi, apogeo e crisi nell'elaborazione dottrinale italiana (sec. XIV-XVI). Turin 2003, S. 54. 
Aufwertung des Kämpendienstes und seine Integration in die zeitgenössische Rechtskultur finden sich ebenfalls im 1360 verfassten Duelltraktat des Bologneser Juristen und Kriegstheoretikers Giovanni da Legnano († 1383), und auch Paride del Pozzo (1410-1493), unbestrittener „padre de duellisti“, 8 verglich in seinem zwischen 1475 und 1478 verfassten Traktat ,Duello' die Kämpen mit juristischen Doctores in anwaltlichen Diensten: [P] erche sono simili ali doctori iuristi che sono aduocati nele cause civile. ${ }^{9}$

Gleichwohl konnte der Befund, dass die Lohnkämpfer - ich zitiere Hermann NotTARP - „kraft Gewerbes unehrlich, hergelaufenes Volk, später vielfach fahrende Ritter“ gewesen seien, in der deutschen Forschung bereits für das Frühmittelalter Geltung beanspruchen. ${ }^{10}$ Hatte nicht die ,Lex Frisionum“ von 802/ 803 den campio an erster Stelle zu denjenigen Menschen gerechnet, „die ohne Buße getötet werden können“? ${ }^{11}$ Allerdings heißt es in einem anderen Titulus des Friesenrechts: „Wenn der Zweikämpfer, der mit Sold gedungen ist, getötet wird, [...] zahle der, der ihn gedungen hat, den Mannwert des getöteten Mannes. "12 Nimmt man hinzu, dass in der ,Lex Baiuvariorum' aus der ersten Hälfte des 8. Jahrhunderts für denselben Fall ebenfalls die Zahlung des Wergelds durch den Auftraggeber - und eben nicht seinen Gegner - vorgesehen ist, ,weil er [den Kämpen] für eine unrechtmäßige Sache gemietet hatte“, ist mit Blick auf das frühe Mittelalter kaum von einer generellen Rechtlosigkeit der Lohnkämpfer auszugehen. ${ }^{13}$ Zumindest für das Spätmittelalter aber schien mit Rekurs auf die

8 Marco Cavina, Il sangue dell'onore. Storia del duello, Rom, Bari 2005, S. 53. Zu Paride del Pozzo siehe auch Ennio Cortese, Sulla scienza giuridica a Napoli tra Quattro e Cinquecento. In: Manlio Bellomo (Hg.), Scuole, diritto e società nel Mezzogiorno medievale d'Italia. Bd.1. Catania 1985, S. 33-133, bes. S. 89-96, und Cavina (Anm. 7), S. 90 f.

9 Giovanni da Legnano (Anm. 6), lib. VI, pars 7, c. clxxxii, S. 190: Vt dictum est, hic aequiparatur campio advocato, sicut igitur quilibet admittitur ad postulandum. Zu Giovanni da Legnano vgl. auch Peter Thorau, Lignano (Legnano), Johannes v. In: Lexikon des Mittelalters. Bd. 5 (1991), Sp. 1977 f.; Paride del Pozzo, Duello, libro de re, imperatori, principi, signori, gentilhomini et tutti armigeri. Venedig 1530 , lib. V, c. V, unpag.

10 Hermann Nottarp, Gottesurteilsstudien (Bamberger Abhandlungen und Forschungen 2). München 1956, S. 301. Vgl. auch Dieter Brennecke, Lohnkämpfer. In: Handwörterbuch zur deutschen Rechtsgeschichte. Bd. 2 (1978), Sp. 31 f.

11 Lex Frisionum. Hrsg. v. Karl August Eckhardt u. Albrecht Eckhardt (MGH Fontes iuris Germanici antiqui 12). Hannover 1982, tit. V, §1, S. 47: Titulus V. De hominibus qui sine compositione occidi possunt. §1. Campionem [...].

12 Ebd., tit. XIIII, §7, S. 60: Si campio, qui mercede conductus est, occisus fuerit, qui eum conduxit [...] insuper et leudem occisi hominis exsolvat.

13 Lex Baiuvariorum. Hrsg. v. Georg Heinrich Pertz (MGH Leges 3). Hannover 1863, c. XVIII, $\S 1$, S. $327 \mathrm{f} .:$ Si unus ex his ab altero interfectus fuerit, quamvis nobilis sit persona, non conpona- 
zitierte Stelle des Sachsenspiegels, aber auch nahezu gleichlautende Passagen des Deutschen- und Schwabenspiegels festzustehen, dass den Kämpen eine rechtliche Randexistenz attestiert werden muss. ${ }^{14}$ Als Vertreter eines fahrenden, unehrlichen Gewerbes in disqualifizierender Nähe zu den spilluten seien die Kampfstellvertreter von einschneidenden Sanktionen betroffen, die auf ihre Tätigkeit, nicht auf ihre soziale Befindlichkeit rekurrierten: Der Verlust der Gerichtsfähigkeit und der Ausschluss aus der Rechtsgemeinschaft seien in diesem Zusammenhang ebenso $\mathrm{zu}$ nennen wie eine soziale Distanzierung und die Rechtlosigkeit im Sinne des Prozessrechts. ${ }^{15}$ Nun ist aber mit Ernst Schubert darauf hinzuweisen, dass Eike von Repgow und seine Nachfolger „ein Recht, so wie sie es ,erkannten', spiegelten, nicht aber die soziale Wirklichkeit."16 Denn wie für das fahrende Volk insgesamt gilt auch für die mit einem Federstrich der Forschung pauschal rechtlos gestellten Lohnkämpfer des Mittelalters - ich zitiere nochmals Ernst SCHUBERT:

Die Rechtsspiegel haben hier mehr auf die Wissenschaft eingewirkt als auf ihre Zeitgenossen. Vor allem: Bis auf wenige Ausnahmen wurde die Unehrlichkeit als ein starres und damit strenges juristisches Gebilde beschrieben. Weltfremder Dogmatismus. ${ }^{17}$

tur amplius quam 12 solidis: et ab eo componitur, qui illum iniuste invitavit. Vgl. dazu insgesamt Brennecke (Anm. 10), Sp. 32, und Neumann (Anm. 3), S.184, Anm. 977.

14 Vgl. Deutschenspiegel und Augsburger Sachsenspiegel. Hrsg. v. Karl August Eckhardt, Alfred Hübner (MGH Fontes iuris germanici. NS 3). 2. Aufl. Hannover 1933, Landrecht, c. 41, § 2, S. 117: Kemphen und iriu kint [...], die sint alle rehtelôs; Schwabenspiegel, Landrecht, §411 (Summarie von kunglichen und keyserlichen darzu landt und lehen rechten, Augsburg, um 1475, Bl. 76r. http://digi.ub.uni-heidelberg.de/diglit/schwabenspiegel1475/0165 [Zugriff: 17.03.2012]): Der eines mannes eeweib zu einer huren macht, oder ein maget oder ein weib notzygot, nimmet er sy darnach zu der ee das seyen kempffen und ire eekint, und alle die uneelich geboren sein, oder die diepheit, oder den straßraub vergolten hond, unnd des mit gericht beczwungen seind, oder haut oder har erlediget hon vor gericht die seind alle rechtloß. Vgl. dazu auch Brennecke (Anm. 10), Sp. 32.

15 Vgl. Hans-Peter Hils, Reflexionen zum Stand der hauptberuflichen Fechter des Späten Mittelalters unter Berücksichtigung historischer Rechtsquellen. In: Gundolf Keil (Hg.), Würzburger Fachprosa-Studien. Beiträge zur mittelalterlichen Medizin-, Pharmazie- und Standesgeschichte aus dem Würzburger medizinhistorischen Institut. Michael Holler zum 60. Geburtstag (Würzburger Medizinhistorische Forschungen 38). Würzburg 1995, S. 201-219, hier 204. Vgl. auch Ernst Schubert, Fahrendes Volk im Mittelalter. Bielefeld 1995, S. 235 f.; ders., Vom Zweikampf zum Duell (Studentengeschichtliche Vereinigung des C[oburger]C[onvents]. Sonderheft). Stuttgart 1984, S. 5.

16 Schubert (Anm. 15), S. 235.

17 Ebd., S. $111 \mathrm{f}$. 
Jenseits solcher statischer rechtssystematischer Setzungen schlage ich eine dynamischere Lesart vor, die einerseits die historiographische Rede von der kategorischen Marginalität der spätmittelalterlichen Kämpen sachdienlich zu relativieren sucht. Andererseits wird es darum gehen, das Spektrum zeitgenössischer Praxen und Perzeptionen in seiner (rechts-)pragmatischen Aushandlungslogik $\mathrm{zu}$ rekonstruieren. ${ }^{18} \mathrm{Zu}$ Recht wird in der aktuellen Marginalitätsforschung eingefordert, soziale und kulturelle Randphänomene in ihrer relationalen Dynamik zu begreifen und sich verstärkt mit konkreten, diskursiven Erzeugungen von Integrations- und Exklusionsmomenten zu beschäftigen. ${ }^{19}$ Im Falle der städtischen Kämpen tritt dabei ein komplexes Wechselspiel von punktuellen Marginalitätsbehauptungen, funktional orientierten Integrationsbemühungen im Sinne der Rechtspflege und Zuschreibungen professionsspezifischer Ambiguität vor Augen. Die genuine Repräsentationsaufgabe des Lohnkämpfers, einen fremden Rechtsstandpunkt mit dem eigenen Körper verteidigen zu müssen, brachte eine eigentümliche Gratwanderung zwischen eigenen und fremden Handlungsund Rollenerwartungen mit sich, die, wenn nicht eo ipso zu einer sozialen und rechtlichen Randexistenz, doch zu einem latenten Verdachtsmoment gegenüber der beruflich ausgeübten Kampfstellvertretung führte. Um die Institution des professionellen Kämpen in seiner pragmatischen Funktionalität für den Gerichtszweikampf des späteren Mittelalters zu beleuchten, vermag ein Blick in die Stadtrechts- und Rechnungsüberlieferungen deutscher und italienischer Städte mehr Aufschluss zu geben als einige dürre Sätze in den Rechtsspiegeln.

18 Zur Pendelbewegung von Dekonstruktion und Rekonstruktion im Rahmen der Marginalitätsforschung siehe Bernd-Ulrich Hergemöller, „Randgruppen“ im späten Mittelalter. Konstruktion - Dekonstruktion - Rekonstruktion. In: Hans-Werner Goetz (Hg.), Die Aktualität des Mittelalters (Herausforderungen. Historisch-politische Analysen 10). Bochum 2000, S. 165-190.

19 Vgl. dazu Moritz Wedell, Marginalität und Raumsemantik. Zur Einleitung. In: Nicole Nyffenegger, Thomas Schmid u. ders. (Hgg.), Marginalität im Mittelalter. In: Das Mittelalter. Perspektiven mediävistischer Forschung 16/2 (2011), S. 9-16, bes. S. 14; ders., Bilanz. Anmerkungen zum Begriff der Marginalität. In: ebd., S. 142-159, bes. S. 144 u. 158. Zu Problemen und Perspektiven der Marginalitätsforschung allgemein siehe Frank Rexroth, Mediävistische Randgruppenforschung in Deutschland. In: Michael Borgolte (Hg.), Mittelalterforschung nach der Wende (Historische Zeitschrift. Beiheft NF 20). München 1995, S. 427-451; Bernd-Ulrich Hergemöller, Randgruppen der spätmittelalterlichen Gesellschaft. Wege und Ziele der Forschung. In: Ders. (Hg.), Randgruppen der spätmittelalterlichen Gesellschaft. Ein Hand- und Studienbuch. 2. Aufl. Warendorf 1994, S. 1-55. Vgl. auch Frank Rexroth, Grenzen der Stadt, Grenzen der Moral. Der urbane Raum im Imaginarium einer vormodernen Stadtgesellschaft. In: Peter Johanek (Hg.), Die Stadt und ihr Rand (Städteforschung A 70). Köln, Weimar, Wien 2008, S.147-165, und den für die deutsche Forschungslandschaft - Pionieraufsatz von František Graus, Randgruppen der städtischen Gesellschaft im Spätmittelalter. In: Zeitschrift für historische Forschung 8 (1981), S. 385-437. 
In besonderer Weise ist dabei den Rahmenbedingungen und Kontrollmechanismen nachzugehen, die die Tätigkeit der Kämpen in städtischen Diensten flankierten, um potentielle Eigeninteressen der Lohnkämpfer zugunsten ihrer Vertretungsfunktion $\mathrm{zu}$ neutralisieren und das manipulationsanfällige Entscheidungsverfahren des Zweikampfs möglichst ergebnisoffen und gerecht zu gestalten. Zur Klärung dieser Zusammenhänge ist nun im Folgenden zunächst nach dem Sitz des gerichtlichen Zweikampfes und der Kampfstellvertretung im städtischen Rechtsleben zu fragen. Entgegen dem gängigen Bild des pauschal rechtlosen Kämpen können dabei Faktoren einer städtischen Institutionalisierung des officium campionatus abgeleitet werden - Vergütung, Verfahrenskontrolle und Qualifikation -, die auf ein geregeltes Gewerbe hindeuten, zugleich aber den campio als zwischen Marginalität, Manipulation und Rechtspflege schillernde Figur ausweisen.

\section{Die Stadt und ihre ,Zweikämpfer‘}

Der besondere Friedensraum der Stadt als Untersuchungsfeld der Zweikampfforschung ${ }^{20}$ mag zunächst nicht eben naheliegend erscheinen, galt doch, ausgehend vom Paradigma des urbanen Rationalitätsvorsprungs in der liberalen Stadtgeschichtsschreibung des 19. Jahrhunderts, ${ }^{21}$ der Typus des Stadtbürgers

20 Vgl. die jüngsten Publikationen zu gerichtlichem Zweikampf und Ehrenduell: Ulrike Ludwig, Barbara Krug-Richter u. Gerd Schwerhoff (Hgg.), Das Duell. Ehrenkämpfe vom Mittelalter bis zur Moderne (Konflikte und Kultur - Historische Perspektiven 23). Konstanz 2012; Neumann (Anm. 3); Uwe Israel u. Gherardo Ortalli (Hgg.), Il duello fra medievo ed età moderna. Prospettive storico-culturali (I libri di Viella 92). Rom 2009; Uwe Israel, Wahrheitsfindung und Grenzsetzung. Der Kampfbeweis in Zeugenaussagen aus dem frühstaufischen Oberitalien. In: Quellen und Forschungen aus italienischen Archiven und Bibliotheken 88 (2008), S. 119-147.

21 Vgl. hierzu Peter Johanek, Mittelalterliche Stadt und bürgerliches Geschichtsbild im 19. Jahrhundert. In: Gerd Althoff (Hg.), Die Deutschen und ihr Mittelalter. Themen und Funktionen moderner Geschichtsbilder vom Mittelalter (Ausblicke). Darmstadt 1992, S. 81-100; Luise Schorn-Schütte, Stadt und Staat. Zum Zusammenhang von Gegenwartsverständnis und historischer Erkenntnis in der Stadtgeschichtsschreibung der Jahrhundertwende. In: Die alte Stadt. Zeitschrift für Stadtgeschichte, Stadtsoziologie und Denkmalpflege 10 (1983), S. 228-266; Klaus Schreiner, Die Stadt des Mittelalters als Faktor bürgerlicher Identitätsbildung. Zur Gegenwärtigkeit des mittelalterlichen Stadtbürgertums im historisch-politischen Bewußtsein des 18., 19. und 20. Jahrhunderts. In: Cord Meckseper (Hg.), Stadt im Wandel. Kunst und Kultur des Bürgertums in Norddeutschland 1150-1650. Ausstellungskatalog. Bd. 4. Stuttgart-Bad Cannstatt 1985, S. 517-541; ders., „Kommunebewegung“ und „Zunftrevolution“. Zur Gegenwart der mittelalterlichen Stadt im historisch-politischen Denken des 19. Jahrhunderts. In: Franz Quarthal u. Wil- 
nach Walter SchAufELBERGER als eher dem „friedlichen Arbeits- und Erwerbsgang“22 zugeneigt. Entsprechend stellte etwa Hermann NotTARP mit Blick auf die städtische Haltung zu Gottesurteilen fest: „Der Händler ist kein Kämpfer“, zumal dem Städter ohnehin die für die Relevanz der Gottesurteile notwendige „Naturverbundenheit“ abgehe.23 Infolgedessen erscheint es geradezu zwangsläufig, dass aus städtischen Privilegien eine generelle Distanz des progressiv gedachten Stadtbürgertums $\mathrm{zu}$ vermeintlich primitiv-irrationalen Mitteln der Wahrheitsfindung abgeleitet wurde: ${ }^{24}$ Angefangen beim vorstädtischen Kaufmannsrecht und zwischenstädtischen Verträgen ersuchten zahlreiche Städte zwischen dem 12. und 14. Jahrhundert um Zweikampfbeschränkungs- oder Befreiungsprivilegien, ${ }^{25}$ die unterschiedliche Restriktionsradien annehmen konnten und erkennbar einen gewissen einzelfallbezogenen Aushandlungsspielraum beließen. Entweder darf der Fremde den Bürger nicht zum Zweikampf fordern, wenn nicht die Herausforderung der Bürger zum duellum allgemein verboten wird, oder den Bürgern wird eingeräumt, dass sie trotz kämpflicher Ansprache den Reinigungseid leisten können oder den Zweikampf nicht außerhalb der Stadt, nicht von ihren Mitbürgern und nur bei schweren Vergehen annehmen müssen. ${ }^{26}$ Diese städtische Exemtionswelle, die aber keinesfalls mit einer mentalitätsbedingten Generalablehnung verwechselt werden sollte, wurde meist mit pragmatischen Erwägungen der tonangebenden Kaufleute erklärt, denen die oft langwierige Prozedur des gerichtlichen Zweikampfs als Beschwernis für Handel und Wandel gegolten habe. ${ }^{27}$ Noch entscheidender scheint mir aber Robert BARTLETTS Hinweis zu sein, dass diese Privilegierungen vor allem auf die Befreiung von Herrschaftsrechten abzielten, die mit der Aufsicht über den gerichtlichen Zweikampf zusammenhingen und mit den recht-

fried Setzler (Hg.), Stadtverfassung, Verfassungsstaat, Pressepolitik. Festschrift für Eberhard Naujoks zum 65. Geburtstag. Sigmaringen 1980, S. 139-168.

22 Walter Schaufelberger, Der Wettkampf in der alten Eidgenossenschaft. Zur Kulturgeschichte des Sports vom 13. bis ins 18. Jahrhundert (Schweizer Heimatbücher 156/158). Bern 1972, S. 62. Vgl. dazu auch B. Ann Tlusty, The Martial Ethic in Early Modern Germany. Civic Duty and the Right of Arms (Early Modern History. Society and Culture). Houndmills, Basingstoke 2011, S. 94; Robert Bartlett, Trial by Fire and Water. The Medieval Judicial Ordeal. Oxford 1986, S. 54 f.

23 Nottarp (Anm. 10), S. 192.

24 Vgl. Bartlett (Anm. 22), S. 54.

25 Vgl. ebd., S. 55-60; Neumann (Anm. 3), S. 55-60; Bernhard Diestelkamp, Die Städteprivilegien Herzog Ottos des Kindes, ersten Herzogs von Braunschweig-Lüneburg (1204-1252) (Quellen und Darstellungen zur Geschichte Niedersachsens 59). Hildesheim 1961, S. 44-47, 194, 248 f.; Hartmut Boockmann, Die Stadt im späten Mittelalter. München 1986, S. 150.

26 Vgl. Nottarp (Anm. 10), S. 192f.; Patetta (Anm. 7), S. 471; Neumann (Anm. 3), S. 57-59.

27 Vgl. Neumann (Anm. 3), S. 56-58; Schubert (Anm. 15), S. 6. 
lichen Autonomiebestrebungen der Stadtbürger kollidierten..$^{28}$ Ungeachtet dieser Privilegierungsvorgänge waren aber die spätmittelalterlichen Städte keineswegs eine „duellfreie Zone“: ${ }^{29}$ Zum einen hatten die Magistrate damit zu rechnen, städtische Rechtspositionen gegebenenfalls mit dem Beweismittel des gerichtlichen Zweikampfs zu verteidigen, zum anderen waren auch nach dem Aufkommen der Exemtionsprivilegien Zweikämpfe in den Städten durchaus präsent. ${ }^{30}$ So hatte zwar Nürnberg bereits 1219 von Friedrich II. eine Zweikampfbefreiung erwirkt - „Niemand im ganzen Römischen Reich darf einen Bürger dieses Ortes zu einem duellum herausfordern“, heißt es in der Urkun$\mathrm{de}^{31}$-, andererseits wurde den Nürnbergern ein Zweikampf gegen Fremde vorbehaltlich einer Anhörung vor dem Rat noch im 15. Jahrhundert ausdrücklich zugestanden. ${ }^{32}$ Wiederum anders liegt der Fall der ober- und mittelitalienischen Stadtkommunen, deren Magistrate im Nachgang des Friedens von Konstanz 1183 häufig das vorher von Grafen und Bischöfen ausgeübte Herrschaftsrecht der Zweikampfaufsicht mittels kaiserlicher Privilegierungen an sich zu ziehen vermochten. ${ }^{33}$ Infolgedessen nehmen Vorschriften zum gerichtlichen Zweikampf und zur Kampfstellvertretung in den kommunalen Statutensammlungen des 13. Jahrhunderts einen festen Platz ein. ${ }^{34}$

28 Vgl. Bartlett (Anm. 22), S. 60f. Vgl. dazu auch eine Zeugenaussage über die Abhängigkeit San Gimignanos vom Bischof von Volterra aus dem Jahr 1238, die gerade an dessen Aufsichtsrecht über gerichtliche Zweikämpfe im Territorium von San Gimignano festgemacht wurde: Robert Davidsohn (Hg.), Forschungen zur Geschichte von Florenz. Bd.2: Aus den Stadtbüchern und -Urkunden von San Gimignano (13. und 14. Jahrhundert). Berlin 1900, Nr. 2390, S. 315: Andreas q. Alberti [...] dicit quod vidit dominum Ildebrandum episcopum (Bf. von Volterra 1184$1211, \mathrm{Anm} . \mathrm{RD}$ ) tenere in hac terra (S. Gimignano, Anm. $\mathrm{RD}$ ) prelium judiciarium inter Raltonem et patrem ex parte una, et Bonajunta de Casolello ex altera.

29 Neumann (Anm. 3), S. 60.

30 Vgl. ebd.; Bartlett (Anm. 22), S. 56; Wolfgang Leiser, Süddeutsche Land- und Kampfgerichte des Spätmittelalters. In: Württembergisch-Franken 70 (1986), S. 5-17, hier S. 14 f.

31 Privileg Friedrichs II. an Nürnberg, 8. November 1219. In: Friedrich Keutgen (Hg.), Urkunden zur städtischen Verfassungsgeschichte (Ausgewählte Urkunden zur deutschen Verfassungsund Wirtschaftsgeschichte 1). Berlin 1901, S. 194: Nemo aliquem civem loci illius duello impetere debet in toto imperio Romano. Vgl. dazu Leiser (Anm. 30), S. 15.

32 Vgl. Werner Schultheiß (Hg.), Satzungsbücher und Satzungen der Reichsstadt Nürnberg aus dem 14. Jahrhundert (Quellen zur Geschichte der Stadt Nürnberg 3). Nürnberg 1965, Nr. 12, S. 63; Nr. 139, S. 147: daz kein purger keynen gast schol kempflich ansprechen, er chume dan vor e zu den purgeren in den rat und laze verhoren sein sach, ob si gerecht sei. Vgl. Leiser (Anm. 30), S. 15.

33 Vgl. Patetta (Anm. 7), S. 436f.; Antonio Pertile, Storia del diritto italiano dalla caduta dell'impero romano alla codificazione. Bd.6/1: Storia della procedura. 2. Aufl. Bologna 1966, S. $345 f$.

34 Vgl. Patetta (Anm. 7), S. 424f. Zur ober- und mittelitalienischen Statutengesetzgebungen allgemein siehe z. B. Jörg W. Busch, Einleitung. Schriftkultur und Recht am Beispiel der Statuten- 


\section{Institutionalisierungsfaktor: Vergütung}

Diesseits wie jenseits der Alpen lassen sich aus der städtischen Quellenüberlieferung drei Faktoren ableiten, die deutlich in Richtung auf eine städtische Institutionalisierung des Kämpendienstes und einen festen Sitz dieser professionalisierten ,Zweikämpfer' in der urbanen Rechtspflege weisen. Dabei ist erstens an die Vergütung der Lohnkämpfer zu denken, die sowohl aus normativen Tarifordnungen als auch aus Stadtrechnungen zu erschließen ist. Gerade das Faktum der finanziellen Vergütung kann als definierende Essenz der campio-Funktion gelten, erklärt doch etwa die um 1325 entstandene Glosse Johanns von Buch zum Sachsenspiegel-Landrecht zum Wort kempen lapidar: Dit weren lude, de striden vmme gelt. ${ }^{35}$ Auch wenn etwa in England oder der Normandie ein campio locatus, ein Mietkämpe, von der gegnerischen Partei in seiner Funktion als Zeuge zurückgewiesen werden konnte, ${ }^{36}$ erweisen englische Kämpenverträge des 12. und 13. Jahrhunderts mit ihren fein nach einzelnen Verfahrensschritten abgestuften Vergütungsvereinbarungen, dass gerade kirchliche Institutionen auf die nach Vivian H. GALBRAITH „most expensive luxury“ von Lohnkämpfern nicht verzichten konnten. ${ }^{37}$ Nicht nur in England, auch in den Stadtkommunen diesseits und jenseits der Alpen geriet der Kämpendienst nach Federico Patetta

codices. In: Hagen Keller u. ders. (Hgg.), Statutencodices des 13. Jahrhunderts als Zeugen pragmatischer Schriftlichkeit. Die Handschriften von Como, Lodi, Novara, Pavia und Voghera (Münstersche Mittelalter-Schriften 64). München 1991, S.1-14; Hagen Keller, Die Veränderung gesellschaftlichen Handelns und die Verschriftlichung der Administration in den italienischen Stadtkommunen. In: Ders., Klaus Grubmüller u. Nikolaus Staubach (Hgg.), Pragmatische Schriftlichkeit im Mittelalter. Erscheinungsformen und Entwicklungsstufen. Akten des Internationalen Kolloquiums 17.-19. Mai 1989 (Münstersche Mittelalter-Schriften 65). München 1992, S. 21-36; ders., Oberitalienische Statuten als Zeugen und als Quellen für den Verschriftlichungsprozeß im 12. und 13. Jahrhundert. In: Frühmittelalterliche Studien 22 (1988), S. 286-314.

35 Glossen zum Sachsenspiegel-Landrecht. Buch'sche Glosse. Hrsg. v. Frank-Michael Kaufmann. Bd. 1 (MGH Fontes iuris Germanici antiqui 7, 1). Hannover 2002, S. 328.

36 Vgl. Vivian H. Galbraith, The Death of a Champion (1287). In: Richard William Hunt u. a. (Hgg.), Studies in Medieval History presented to Frederick Maurice Powicke. Oxford 1948, S. 283-295, hier S. 286f.; Lea (Anm. 2), S. 169f. Siehe dazu auch zwei Fälle aus Select Pleas of the Crown. Hrsg. v. Frederic William Maitland. Bd.1: A. D. 1200-1225. London 1888, Nr.192, S. 124f.: Et Hamon dicit quod in quadam parte recordantur bene et in quadam parte parum, quia quando Elias vocatus fuit ad warantum et warantavit equam Edwardo, ipse calumpniatus fuit quod ipse Elias fuit campio locatus, et quod idem Edwardus conduxerat eum pro pecunia sua ut deveniret warantus [...]; ebd., Nr. 202, S. 137: Et bene dicunt quod hoc appellum faciunt per odium et athiam, et petit sibi allocari quod appellum illud faciunt per quendam campionem conductum scilicet predictum Stephanum qui pridie fecit duellum apud Hunt'.

37 Vgl. Galbraith (Anm.36), bes. S. 290; William Brown, Trial by Combat, in: Yorkshire Archaeological Journal (1915), S. 300-307; George Neilson, Trial by Combat. New York 1891, S. 48 
$\mathrm{zu}$ einem „mestiere lucroso“,38 einem gewinnbringenden Berufsstand, der für seine risikoreiche Tätigkeit auf zweierlei Weise entlohnt wurde: Entweder in Form einer exklusiven „Festanstellung“ als städtischer Kampfstellvertreter inklusive einer stabilen monatlichen Besoldung aus der Stadtkasse und anlassbedingter Sondervergütungen oder in Form eines „freien Unternehmertums“, das temporär für ein Zweikampfereignis rekrutiert und entsprechend auftragsgebunden entlohnt wurde. ${ }^{39} \mathrm{Zu}$ Recht hat Sarah Neumann darauf hingewiesen, dass gerade die Existenz fest bestallter städtischer Kämpen den vom Sachsenspiegel transportierten sozialen Statusbefund des rehtelôsen kemphen relativiert. ${ }^{40}$ Allerdings ist darauf zu achten, nicht vorschnell städtische Kämpen aus den Quellen herauslesen zu wollen: So mutiert etwa der noster pugil, den Hermann NotTARP als Lohnkämpfer der Stadt Ratingen zu identifizieren glaubte, bei genauerer Lektüre des Referenztextes von 1276 zum Kämpen des Herzogs von Berg, der mittels des Zweikampfs ein in Ratingen von einem Stadtfremden begangenes Kapitalverbrechen erweisen sollte. ${ }^{41}$ Evident wird der Kämpe als städtischer Angestellter am ehesten anhand der kommunalen Rechnungsüberlieferung. In den Ausgaberegistern der Stadt Aachen etwa sind im ganzen 14. Jahrhundert, klassifiziert unter den famuli civitatis bzw. der steede gesinde, Auszahlungen an duo pugilatores oder zwen kempen belegt, die in der ersten Jahrhunderthälfte monatlich 1 Mark, im letzten Viertel des Jahrhunderts aufgrund des gesunkenen Münzwertes 2 Mark van yren loen erhielten, zuzüglich Einkleidung auf Stadtkosten. ${ }^{42}$

f.; Charles Dufresne Du Cange, Campiones. In: Glossarium mediae et infimae latinitatis. Bd. 2. (1842), S. 65-70, hier S. 67.

38 Patetta (Anm. 7), S. 427.

39 Neumann (Anm. 3), S. 185; Hans-Peter Hils, Meister Johann Lichtenauers Kampf des langen Schwertes (Europäische Hochschulschriften. Serie 3, 257). Frankfurt a. M. 1985, S. 232 f.

40 Vgl. Neumann (Anm. 3), S. 184-186.

41 Vgl. Nottarp (Anm.10), S.302. Vgl. Urkundenbuch für die Geschichte des Niederrheins. Hrsg. v. Theodor Joseph Lacomblet. Bd. 2. Düsseldorf 1846, Nr. 696, S. 407: Si vero advena aliquis in ipso opido nostro pro aliquo crimine capitali fuerit allocutus, seu etiam arrestatus, illum nos et nostril successores, si voluerimus, per nostrum pugilem conuincere possumus crimen sibi impositum perpetrasse; et hoc nobis et nostris volumus successoribus specialiter reseruari.

42 Aachener Stadtrechnungen aus dem XIV. Jahrhundert nach den Stadtarchiv-Urkunden mit Einleitung, Registern und Glossar. Hrsg. v. Johannes Theodor Laurent. Aachen 1866, S. 12. Siehe die entsprechenden Belegstellen: 1338 (ebd., S. 129f.): It. Nicolao Stocart de precio suo $13 \mathrm{~m}$. It. ... Beysennecken de precio suo 13 m.; It. de tunicis Stocartz \& .. Beyssenecken 4 m. \& 5. s.; 1344 (ebd., S. 156, 158): It. .. Stocart \& Byssenecken dat. in vocationem duelli Golini 12 m. It. eisdem de duabus tunicis pugillatoriis 12 m.; It. .. Stocart \& Byssenecken de precio eorum 26 m.; 1346 (ebd., S. 187): It. Clos Stocart de precio suo $13 \mathrm{~m}$. It. .. Byssenecken de precio suo $13 \mathrm{~m}$. It. pro tunicis eorumdem 9 m.; 1349 (ebd., S. 226): Sequitur nunc de precio famulorum civitatis. [...] It. Clos Stocart 13 m. per rel. It. .. Byssenecken 13 m. per rel. It. eisdem pro tunicis 8 1/2 m. per rel.; 1376 (ebd., S. 241f.): It. pro vestibus magistrorum \& famulorum civitatis [...] duobus pugillatoribus. [...] 
Als 1338 im Rahmen eines Konfliktes zwischen der Stadt Aachen und Harkrad von Schoynecken ein gerichtlicher Zweikampf drohte, wurden die beiden städtischen Kämpen mit Namen Scotard und Beysennecken aus dem Stadtsäckel auf den Ernstfall vorbereitet: Für 25 kleine Goldgulden oder 33 Mark 9 Schillinge nebst Kleidung erteilte ihnen ein Meister Wiricus Unterricht im Nahkampf; zudem wurden Meister Wiricus, sein famulus und die Kämpen in dieser ,Trainingsphase ‘ auf städtische Kosten verköstigt. ${ }^{43}$ Nachdem der Zweikampf angesagt worden war, wurden die Streitkolben mit Riemen und die beiden Kämpen mit Gürteln und leinenen Hosen versehen: It. pro duobus kampkluppel preparandis corrigeis \& zonis 2 Schillinge, It. pro cingulis pugillatorum 11 Schillinge, It. pro lineis bracis pugillatorum $4 \frac{1}{2}$ Schillinge. ${ }^{44}$ Bedenkt man die Tatsache, dass die beiden Aachener Stadtkämpen mindestens elf Jahre lang, von 1338 bis 1349, kontinuierlich in dieser Funktion tätig und in Aachen sesshaft waren, ${ }^{45}$ ist die häufig zu lesende Identifikation der Kämpen als unstet-fahrendes und deshalb marginalisiertes Gewerbe zu revidieren.

It. pugillatoribus de precio eorum 4 m.; 1385 (ebd., S. 297): It. der steede gesinde [...]. It. den zwen kempen 4 m.; Monatsrechnungen ohne Jahreszahl (vermutlich 1386) (ebd., S. 362): It. den zwen kempen 4 m.; 1390 (ebd., S. 374): It. den zwen Kempen van yren loen 4 m. [...] It. den zwen kempen umb yr roecke 20 m.; 1394 (ebd., S. 390): It. den zwen kempen 4 m.

43 Aachener Stadtrechnung von 1338. In: Ebd., S. 121: Sequitur nunc factum dni. Harcradi de Schoynnecken. Primo, magistro Wirico, qui docuit Stocardum \& Beyssenecken 21 aureos parvos, valent 29 m. \& 4 s. Residuos quatuor aureos \& vestes dederunt magistri civium precedentes. It. famulo ipsius magistri Wirici dat. ad debibendum $1 \mathrm{~m}$. It. de hospicio eorumdem in domo .. Pollicis $2 \mathrm{~m}$. It. de expensis eorundem \& eciam pugillatorum per Jo. Mallart $40 \mathrm{~m}$. $3 \mathrm{~s}$. Zur Bedeuung des Fechttrainings als Vorbereitung auf den gerichtlichen Zweikampf siehe noch 1529 Andrea Alciato, De singulari certamine. Lyon 1544, c. XXXVIII, S. 71: Qui in stadium certaturus descendere velit, eum oportet sciamachiae peritum esse, ut arte et industria imminentes ictus evitare sciat, et ipse hostem ferire. In London wurde der vermeintliche Axtmörder Walter de Stewton 1220 eigens gegen Kaution aus der Haft im Londoner Tower entlassen, um sich bei einem Fechtmeister für den anstehenden Zweikampf schulen zu lassen - et discere eskirmire. Vgl. dazu Sydney Anglo, The Martial Arts of Renaissance Europe. New Haven, London 2000, S. 7.

44 Aachener Stadtrechnung von 1338. In: Laurent (Anm. 43), S. 122: It. de faccione duelli 29 s. It. pro duobus kampkluppel preparandis corrigeis \& zonis 2 s. hall. It. pro cingulis pugillatorum 11 s. It. pro lineis bracis pugillatorum $41 \frac{2}{2} \mathrm{~s}$. Vgl. auch ebd., S. 12. Der Zweikampf selbst kam allerdings nicht zur Ausführung, denn beide Seiten erzielten vorher eine Einigung (ebd., S. 122): It. quum reconciliatum fuit illo die dni. nostri diu fuerunt invicem, et tunc congregati commederunt cum scabinis in domo Bruxella \& expendiderunt ibi $4 \mathrm{~m}$. \& $3 \mathrm{~s}$. Vgl. zum Aachener Fall auch [ohne Vorname] Feit, Schwerttänze und Fechtschulen in Schlesien, insbesondere in Breslau. In: Zeitschrift des Vereins für Geschichte und Altertum Schlesiens 38 (1904), S. 176-233, hier S. 192.

45 Siehe die Belege oben Anm. 42. 
Aus normativer Perspektive geben die italienischen Statutensammlungen Aufschluss über die Entlohnung von Lohnkämpfern. Generell erfreute sich im Italien des 13. Jahrhunderts der Einsatz von Kämpen beim gerichtlichen Zweikampf weiter Verbreitung: Hodie tamen de consuetudine permittitur cuilibet campionem dare, „Heute ist nach der Gewohnheit jeder Person erlaubt, einen Kämpen zu stellen“, schrieb etwa Roffredo Beneventano in seiner ,Summa de pugna‘. ${ }^{46}$ Ähnliches ist auch in den Statuten von San Gimignano (1255), Parma (1266-1304), Brescia (1277) und Novara (1281) zu lesen. ${ }^{47}$ Regelmäßig werden dabei campioni approbati, d. h. professionelle, zweikampferfahrene Kampfstellvertreter, von den sog. prave oder brave persone unterschieden, die, so das Mailänder Statut von 1216, „noch niemals ein Kampf oder ein Duell bestritten haben“ und wohl ihren Einsatz als mietbare Dienstleistung anboten, ohne professionelle Lohnkämpfer zu sein. ${ }^{48}$ Entsprechend unterschiedlich gestaltet sich auch die Entlohnung dieser beiden nach Kompetenz abgestuften Typen von Kampfstellvertretern, wie aus den Paduaner Statuten von 1236 hervorgeht: „Desgleichen

46 Roffredo Beneventano (Anm. 7), c. II, S. 485. Vgl. Bartlett (Anm. 22), S. 112.

47 Statuten von San Gimignano (1255), lib. II, Rubr. 8 (zit. nach Davidsohn [Anm. 28], S. 317): Et quod pugna non sit per domesticos, sed blavas (!) campiones; Parma (1266-1304) (De ordaliis. Hrsg. v. Peter Browe S. J. Bd. 2: Ordo et rubricae. Acta et facta. Sententiae theologorum et canonistarum. Rom 1933, Nr. 9, S. 18): Et si accusatus per se in propria persona voluerit praeliari, et accusator per alium, det aequalem accusator; Brescia (1277), II.96 (Federico Odorici, Storie bresciane dai primi tempi sino all'età nostra, Bd.7, Brescia 1857, S. 126): Liceat actori campionem dare, et alteri parti liceat si actio (1. actor) dederit; Novara (1281), c. 87 (zit. nach Pertile [Anm.33], S.340, Anm.28): In omnibus causis de quibus duellum iudicabitur, licentiam dabo tam actori quam reo de campione dando, ita tamen ut campiones sint consimiles. Vgl. dazu Lea (Anm. 2), S. $168 \mathrm{f}$.

48 Statut von Mailand (1216), c. 14, 16 (zit. nach Antonio G. G. Merendoni, L’arma e il cavaliere. L'arte della scherma medievale in Italia nei secoli XII-XIV. Rimini 1999, S. 17): Fit autem pugna per campiones; interdum vel per pravas personas quae numquam pugnam sive duellum fecerunt. [...] At si per aliam pravam personam, quae numquam fecit pugnam, contendere voluerit; Padua (1236), c. XXX (Statuti del comune di Padova dal secolo XII all'anno 1285. Hrsg. v. Andrea Gloria. Padua 1873, S. 205): Item nullus campio approbatus in pugna, que fit pro homicidio, habere debeat ultra libras centum deductis expensis que fiunt et fieri consueverunt in comestionibus et potibus. Bravus vero campio non ultra quinquaginta libras habere debeat pro pugna homicidii. In aliis casibus approbatus campio non ultra quinquaginta libras, et bravus non ultra vigintiquinque libras habere possit; San Gimignano (1255), II.8 (siehe Zitat Anm. 47). Patetta (Anm. 7), S. 427, interpretiert die Funktion der pravi oder brave persone folgendermaßen: „[A]ccanto ai campioni, le consuetudini di Milano e gli statuti di Padova ricordano le prave persone, che non fanno veramente professione di campioni, ma prestano però il loro servizio come tali.“ Dagegen Nottarp (Anm. 10), S. 146: „[I]n den Statuten von S. Gimignano von 1255 heißt es ,quod pugna non fit per domesticos sed bravos campiones` [...]; es müssen also Berufskämpen sein; ,il bravo` ist in Italien, wer sich zur Ausführung eines gewagten Unternehmens dingen läßt [...].“ Vgl. dazu auch Enrico Giorgio Levi, Il duello giudiziario. Enciclopedia e bibliografia. Florenz 1932, S. 133. 
soll kein approbierter Kämpe in einem Kampf, der im Falle eines Mordes ausgefochten ist, mehr als 100 Lire bekommen, abzüglich der Ausgaben, die für die Verköstigung anfallen und anzufallen pflegen. Der campio bravus bekommt in einem Mordfall nicht mehr als 50 Lire vergütet. In anderen Rechtsfällen kann der approbierte Kämpe nicht mehr als 50 Lire, der Bravus nicht mehr als 25 Lire verlangen [...].“49 Überhaupt ging es in den Statuten häufig darum, im Zuge der kommunalen Zweikampfaufsicht die Kämpenvergütungen zu begrenzen, zum einen mittels präziser Tariffestlegungen, zum anderen, indem den Organen der Zweikampfaufsicht die Entscheidung über deren Höhe eingeräumt wurde: ${ }^{50}$ So gewähren die Statuten von Treviso aus dem Jahr 1207 dem Kämpen beim Austausch der Kampfespfänder ${ }^{51}$ zehn Lire, für den Einsatz im Zweikampf selbst 50 Lire, die Statuten von Verona (1228) zunächst bei der Vadiation 100 Soldi, nach dem bestrittenen duellum dann 50 Lire für den Vertreter des Klägers und 75 Lire für den Vertreter des Angeklagten. ${ }^{52}$ In den Statuten von Viterbo (1251-1252) wiederum waren als Kämpensold jeweils zehn Lire vorgesehen; kam eine Einigung der Parteien zustande, nachdem die Lohnkämpfer das Feld betreten hatten, erhielten sie jeweils nicht mehr als 40 Soldi. ${ }^{53}$ In Parma 1255 wurden den campiones 15 Lire nebst Verpflegung zugestanden, während schließlich in Novara 1287 eine Maximalsumme von 100 Lire zuzüglich Verköstigung statuiert wur-

49 Statuten von Padua (1236), c. XXX (Gloria [Anm. 48], S. 205): Item nullus campio approbatus in pugna, que fit pro homicidio, habere debeat ultra libras centum deductis expensis que fiunt et fieri consueverunt in comestionibus et potibus. Bravus vero campio non ultra quinquaginta libras habere debeat pro pugna homicidii. In aliis casibus approbatus campio non ultra quinquaginta libras, et bravus non ultra vigintiquinque libras habere possit [...].

50 Statuten von Vercelli (1241), c. 88 (Statuti del comune di Vercelli dell'anno MCCXLI aggiuntivi monumenti storici dal MCCXLIII al MCCCXXXV. Hrsg. v. Giovambatista Adriani. Turin 1877, S.76): Et debeant moderari expensae campionis, arbitrio potestatis vel consulum comunis, qui pro tempore fuerint. Vgl. dazu Pertile (Anm. 33), S. 342.

51 Siehe zum Austausch der Kampfespfänder (lat. vadia duelli, frz. gages de bataille), meist ein Handschuh als Sinnbild der berechtigten Hand, Neumann (Anm. 3), S. 87.

52 Statuten von Treviso (1207) (Gli statuti del comune di Treviso. Hrsg. v. Giuseppe Liberali. Bd.1: Statuti degli anni 1207-1218. Venedig 1950, S.122): Item quod camphyo pro arris duelli accipiat tantum .X. libras et pro duello faciendo .L. libras et non plus sub aliqua occasione. Noch in den Statuten von 1260-1263 findet sich dieser Passus, vgl. Gli Statuti del comune di Treviso (sec. XIII-XIV). Hrsg. v. Bianca Betto. Rom 1986, S. 231. Siehe auch die Statuten von Verona (1228) (zit. nach Pertile [Anm. 33], S. 342, Anm. 36): Nullus camphyo, ararum nomine, ultra 100 solidos suscipiat; - nomine vero precii si fidata fuerit, 50 libras, si desfidata fuerit 75 libr. Vgl. dazu Merendoni (Anm. 48), S. 12.

53 Statuten von Viterbo (1251-1252) (Statuti dell Provincia Romana. Hrsg. v. Vincenzo Federici. Rom 1930, S. 165): [...] quilibet camphio habeat .x. libras, si pro tanto pretio vel salario poterit a Curia inveniri, et si pugna ad recredentiam venerit. si vero intervenerit compositio, postquam in campum prosiluerint camphiones, unusquisque eorum habeat .xl. solidos et non plus. 
de. ${ }^{54}$ Trotz dieser normativen Vergütungsobergrenzen blieb die Beauftragung von Kämpen im Rahmen von gerichtlichen Zweikämpfen ein teures Unterfangen; infolgedessen räumten etwa die Statuten von Novara die Möglichkeit ein, dass der Podestà den armen Verwandten eines Mordopfers hierfür finanzielle Mittel auf Kosten der Kommune zur Verfügung stellen konnte. ${ }^{55}$ Mitunter trat auch der gerichtliche Zweikampf als ein vom Podestà angeordneter und aus dem Stadtsäckel bezahlter Offizialvorgang zutage, ${ }^{56}$ oder der Kläger bzw. der Beklagte war im Falle einer Niederlage seines Kämpen dazu verpflichtet, die Vergütung des gegnerischen Kämpen aus eigenen Mitteln zu bestreiten. ${ }^{57}$ Insgesamt diente die Festsetzung von in ihrer Höhe nicht unbeträchtlichen Kämpentarifen seitens der Stadtkommunen und ihrer Amtsträger nicht zuletzt dazu, den Agon des gerichtlichen Zweikampfs möglichst ausgeglichen zu gestalten und den Ausgang der Rechtsentscheidung von finanziellen Disparitäten bei der Kampfstellvertretung möglichst frei zu halten. ${ }^{58}$ Der hohe, nach Verfahrensschritten gestufte finanzielle Aufwand, der mit der Beauftragung eines Repräsentanten einherging, fügte sich dabei nahtlos in die allgemeine prozedurale Logik des gerichtlichen Zweikampfs ein, die mittels steigender Gebührensätze ein möglichst schnelles Einlenken der Parteien im Sinne einer Rekonziliation zu gewährleisten suchte. Es galt, so Sarah Neumann, die „Maxime, die Auseinandersetzung zu vermeiden“, und dem binären Entscheidungsmoment des kämpflichen Agons durch eine beide Seiten zufriedenstellende Kompromissformel zuvorzukommen. ${ }^{59}$ Dass bereits durch die Indienstnahme von Kämpen ein gehöriger finanzieller Druck auf den Streitparteien lastete, zeigt ein Fall aus San Gimignano: Dort waren 1241 vor dem

54 Statuten von Parma (1255) (zit. nach Merendoni [Anm. 48], S. 20): Et quilibet campio habeat tantum XV libras parmenses et pasturam, et non aliud per se vel per alium aliqua occasione. Vgl. Statuten von Parma (1266-1304) (Browe [Anm.47], Bd.2, Nr.9, S.18); Statuten von Novara (1287) (zit. nach Pertile [Anm.33], S. 342, Anm.36): Campioni non debeat dari pro duello omnibus computatis, excepto cibo et potu, ultra sol. $100 \mathrm{imp}$.

55 Vgl. Patetta (Anm. 7), S. 429.

56 Ebd.

57 Statuten von Vercelli (1241). c. 66 (Adriani [Anm. 50], S. 58-60): [...] et si succubuerit ille qui appellaretur de dampno restituat in duplum dampnum et expensas campionis. Et si ille qui appellatur obtinuerit restituantur ei ab accusatore expense campionis; Statuten von Novara (1287), c. 87 (zit. nach Pertile [Anm.33], S.341, Anm.32): Qui duellum super alium posuerit, restituat expensas victori, si illud amiserit, arbitrio potestatis, ita tamen ut non prestet expensas campioni ultra 5 libr. imp.

58 Vgl. die Statuten von Padua (1236) (Gloria [Anm. 48], S. 205), die im Falle einer Überschreitung der Vergütungsobergrenze eine Rückzahlung des Aufschlags sowie eine Strafgebühr an die Kommune vorsehen: [...] et qui ultra acceperit vel habuerit, acceptum vel habitum restituat et libras vigintiquinque comuni componat.

59 Neumann (Anm. 3), S. 87. 
Stadtkämmerer und dem Podestà die Parteien mit zwei von auswärts geholten Kämpen erschienen, nebst einem Notar, einigen als numptii bezeichneten Kampfwarten und einem sog. banditor, der für die Ausrüstung zuständig war. Bei dieser Gelegenheit leisteten die Parteien dem Kämmerer Kostenvorschüsse von jeweils 25 Lire. Das Kampfzeug war bereits zur Stelle und die Kämpen mit sieben Lire zuzüglich der Kampfkleidung vergütet, geschoren und ordnungsgemäß ausgerüstet, als die beiden Parteien einlenkten: „Bis jetzt haben wir schon einen großen Schaden, weil jeder Kämpe sieben Lire kostet“, woraufhin der Streit auf Vermittlung eines Notars und eines Kämmerers geschlichtet werden konnte. ${ }^{60}$ Bemisst man den transalpinen Entlohnungsbefund im Hinblick auf den sozialen und rechtlichen Status der Kämpen, dann ist deutlich sichtbar, dass die von NEUMANN konstatierte „Differenzierung von bestallten und unbestallten Lohnkämpfern“, die zu einer „allmählichen Abwertung“ und „randständige[n] Existenz“ der letztgenannten Gruppe“ geführt habe, ${ }^{61}$ südlich der Alpen nicht zu ermitteln ist. Hier bot sich für die kommunale Zweikampfpraxis ein Reservoir an campiones approbati und bravi an, die städtischerseits nicht fest besoldet waren, sondern auftragsgebunden entlohnt wurden. Dabei ist aus der nord- und mittelitalienischen Statutenüberlieferung kein Anhaltspunkt für eine soziale oder rechtliche Deklassierung dieser Personengruppen zu entnehmen.

\section{Institutionalisierungsfaktor: Verfahrenskontrolle}

Als weiterer Faktor einer Institutionalisierung des Kämpendienstes ist zweitens die statuarische Verfahrenskontrolle zu benennen: Denn die den Parteien selbst

60 Zeugenaussage von Cambius notarius in der curia comunis $S^{\text {ti }}$ Gem., 22. Juni 1243 (Davidsohn [Anm. 28], S. 316): Cambius notarius juratus XII Kal. Julii dixit, quod interfuit in domo Palmerii Ardovini, ubi Maria promisit [...] Boninsegne [...] restituere totum et quidquid ipse Boninsegna expenderet et solveret occasione pugne, que fieri debebat inter Mariam ex parte una et Riccium ex altera [...] et predicta fuerunt tempore dominatus Arrigi Lucterii (Podestà a. 1241, Anm. RD) et fuerunt de mense Junii, ut credit de mense et vidi venire ad Sum Gemin. pro dicta pugna duos camphiones, set qui fuerunt non recordor; et vidi guarnimenta facta et vestitos, ut credo vestitos, et tonsos sicut consueverunt tondi, quando veniunt ad pugnam et recordor quod audivi Arigum Lutterii querere ab Arrigo Goizi tunc camerario si erat bene sodus a partibus et ille respondit: $a$ qualibet parte habeo XXV libr. [...] et audivi ab utraque parte, quod quilibet camphionum habuerat libr. VII computatis denariis pannorum: et nominatim dixerunt partes inter se: adhuc ora! habemus plus danno, quia quillibet camphionum constat libr. VII et postea dicta discordia fuit comissa in manibus meis et Arigi Goizi et etiam potuimus concordare. Vgl. dazu Nottarp (Anm. 10), S.145f.

61 Neumann (Anm. 3), S. $185 \mathrm{f}$. 
oder städtischen Amtsträgern obliegende Auswahl der Kämpen aus dem genannten Personalreservoir schuf erst die Voraussetzung dafür, den Zweikampf mit Blick auf die körperliche Beschaffenheit und Kampfkompetenz der Akteure ausgeglichen und ergebnisoffen $\mathrm{zu}$ gestalten. ${ }^{62}$ Entsprechend ausführlich beschäftigten sich die Statutensammlungen mit der Aufgabe der coequatio oder adequatio, die den städtischen Amtsträgern in ihrer Aufsichtsrolle über die gerichtlichen Zweikämpfe übertragen wurde:63 In den Statuten von Treviso (12601263) etwa soll der Podestà gegen eine kampfwillige Streitpartei dann einen equalis camphyo aufstellen, wenn die andere Partei offensichtlich unterlegen wäre. ${ }^{64}$ Davon abgesehen ging es in den kommunalen Rechtssatzungen aber meistens um die Auswahl von zwei Kämpen, die in viribus et personis, wie es in den Statuten von Viterbo (1251-1252) heißt, möglichst ähnlich sein sollen, denn: Pugna [...] fiat per pares sive similes sive equales, der „Kampf soll von gleichen oder ähnlichen oder gleichwertigen Kämpfern bestritten“ werden, teilt das Bologneser Statut von 1250 mit. ${ }^{65}$ Insofern war es dem Podestà in Padua implizit anheimgestellt, einen campio nimis fortis, einen allzu starken Kämpen, auch abzulehnen, und in San Gimignano sollten 1314 zwei Mönche damit beauftragt

62 Nach den ,Constitutiones regni Siciliae‘ Friedrichs II. von 1231 war das Prinzip der coequatio auch dann zu berücksichtigen, wenn die Streitparteien selbst gegeneinander antraten (Die Konstitutionen Friedrichs II. für das Königreich Sizilien. Hrsg. v. Wolfgang Stürner [MGH Constitutiones 2. Suppl.]. Hannover 1996, II.40, S. 348): Illud etiam presenti sanctioni duximus adnectendum, ut si is, qui pugnam obtulerit, lesus fuerit in aliqua parte sui corporis, propterea is, qui pugna impetitur, in nullo sue defensionis auxilium minorabit. Ceterum si impetitus forte sit lesus in quacumque parte corporis, que necessaria sit ad pugnam, is, qui eam obtulit in ea parte se debilitare debebit, in qua debelitatus est is, cui duellum offertur, veluti si unum tantum oculum habeat impetitus, is, qui pugnam offert, diebus aliquibus antea illum oculum apposito aliquo sibi claudat, in quo pati dignoscitur accusatus. Similiter et in digitis et in membris aliis hoc volumus obtinere iuxta proborum virorum consilium et discretionum providam judicantis. Auch Alciato (Anm. 43), c. XXIX, S. 52, unterstützt diese Vorgehensweise, stellt aber auch fest: Cum vero per alium aliquis pugnare potest, tunc aequalitas magis requiri solet.

63 Vgl. dazu Pertile (Anm. 33), S. 342; Patetta (Anm. 7), S. 428; Levi (Anm. 48), S. 133, 137; Cavina (Anm. 8), S. 29; Nottarp (Anm. 10), S. 303.

64 Statuten von Treviso (1260-1263) (Betto [Anm. 52], S. 230): Item si de aliqua re vel facto iudicata fuerit pugna, quod sit in arbitrio potestatis utrum velit aut partes per se pugnent vel per camphiones, inspecta qualitate personarum; salvo eo quod unus possit se defendere personaliter, si voluerit, et potestas det contra eum equalem camphyonem, si alter non fuerit ei equalis.

65 Statuten von Viterbo (1251-1252) (Federici [Anm. 53], S. 164): Pugna vero, ubi Constitutio nostro admittitur, ita fiat: Curia Viterbii eligat duos homines equos vel pares de Viterbio, prout sibi videbitur, in viribus et personis; Statuten von Bologna (1250), lib. II, rubr. V (Statuti di Bologna dall'anno 1245 all'anno 1267. Hrsg. v. Luigi Frati. Bologna 1869, S. 259): [...] et si pugna fierit fiat per pares sive similes sive equales, secundum quod melius equari possint arbitrio potestatis [...]. 
werden, zwei Kämpen equalium virium et formae, mit ähnlicher Körperkraft und Gestalt, zu finden. ${ }^{66}$ Das Prinzip der coequatio galt, wie bereits aus den ,Constitutiones regni Siciliae‘ Friedrichs II. von 1231 hervorgeht, auch für die Bewaffnung der Kampfstellvertreter. ${ }^{67}$ So lautet etwa der entsprechende Passus in den Statuten von Parma (1255): „Es sollen vom Rektor der Stadt Parma zwei an Größe und Stärke ähnliche [Kämpen] gefunden werden; und auch ihre Waffen, nämlich Schild und Keule, sollen gleich sein“. ${ }^{68}$ So sehr sich aber die städtischen Amtsträger um eine coequatio der Kräfte und Mittel bemühten, ihre Machbarkeit in der Praxis wurde von Zeitgenossen durchaus skeptisch beäugt. So diente etwa Friedrich II. gerade das skandalon, Rechtsentscheidungen an die niemals kongruente Kampfkraft und -kompetenz von Kämpen zu binden, als Argument für die Abschaffung der monomachia im Königreich Sizilien: „Kaum oder niemals können zwei Kämpen gefunden werden, die so ähnlich sind, dass nicht der Eine im Ganzen stärker bzw. irgendwo an Kraft oder Tugend dem Anderen überlegen ist oder wenigstens von den Anlagen her der Eine den Anderen nicht übertrifft.“69 Gleichwohl erklärte etwa Roffredo Beneventano in seinem Traktat die equa distributio der Kämpen zum Strukturprinzip des Zweikampfs, vergleichbar mit der gleichmäßigen Verteilung der Anwälte im römischen Prozessrecht. $^{70}$

66 Statuten von Padua (1236), c. XXX (Gloria [Anm. 48], S. 205): Si pugna iudicata fuerit, qui agit, campiones de Padua representet potestati, et reus similiter campiones representet potestati, ex quibus representatis potestas ex suo officio cum diligencia campiones qui pugnare debeant, eligat et exequet. [...] si vero campio nimis fortis apparuerit, de ipso sit in arbitrio potestatis, servato modo et ordine statuti; Statuten von San Gimignano (1314) (zit. nach Pertile [Anm. 33], S. 342, Anm. 38): [...] potestas per duos religiosos viros inveniri faciat duos campiones equalium virium et formae, expensis perdentium.

67 Constitutiones regni Siciliae Friedrichs II. In: Stürner (Anm. 62), II.37, S. 345: Statuimus preterea, ut amodo campiones habeant claves equales, non spinosas neque cum agutionibus neque habentes cornua neque ex parte fustis ad modum unguis. Vgl. dazu Levi (Anm. 48), S. 137.

68 Statuten von Parma (1255), zit. nach Merendoni (Anm. 48), S. 21: Et si accusatus per alium volverit praeliari, inveniantur duo aequales tam usibiles quam bravi a rectore civitatis Parma, bona fide sine fraude, in magnitudine et fortitudine; et arma, scilicet scutum et clava, adaequentur in magnitudine et fortitudine; et arma, scilicet scutum et clava, adaequentur [...]. Siehe auch die Statuten von Viterbo (1251-1252). In: Federici (Anm.53), S.164: [...] et habeant duo paria armorum. Vgl. dazu auch Pertile (Anm. 33), S. 342.

69 Constitutiones regni Siciliae Friedrichs II. (1231), II.33 (Stürner [Anm. 62], S. 340): Vix enim, aut nunquam duo pugiles inveniri poterunt sic equales, ut vel in totum non sit alter altero fortior vel quod in aliqua parte sui vigore maiori et potiori virtute vel saltem ingeniis alter alterum non excedat.

70 Roffredo Beneventano (Anm. 7), c. 4, S. 488: Sed illud nota quod quando pugna debet fieri per campionem, debet fieri eorum equa distributio ut et advocatorum, ut C. de postul. l. "providendum", et etiam iure langobardo cavetur quod pugna debeat fieri per similes campiones, ut in 
Um einen möglichst fairen Verlauf und Ausgang des Zweikampfverfahrens zu gewährleisten, trafen viele Statuten Vorkehrungen gegen die vielfältigen Gelegenheiten zur Manipulation des Kampfgeschehens, die sich dem Kämpen bei der Ausübungen seiner kämpflichen Profession eröffneten. ${ }^{71}$ Neben der bereits im langobardischen ,Edictus Rothari‘ und dann im Mailänder Statut von 1216 begegnenden Versicherung, den Kampf nicht mit verbotenen Zaubermitteln wie etwa Kräutern oder Besprechungen zu seinen Gunsten zu beeinflussen, sollte der Kämpe vor Kampfbeginn auch die Wahrheit des von ihm vertretenen Rechtsstandpunkts und seinen persönlichen Einsatz im Zweikampf bona fide, auf Treu und Glauben, beschwören; ${ }^{72}$ im Falle des Betrugs, der offensichtlichen

lomb. qualiter quis se defen. de l. f., sed si fiat inter principales personas, non attendimus equalitatem neque inequalitatem nisi in casibus predictis; principaliter enim pugnabunt. Vgl. Giovanni da Legnano (Anm. 6), lib. VI, pars 7, c. clxxxii, S. 190: Tertio quaero, qualiter in casibus hinc inde, cum conceditur campio, fiet ipsorum datio et concessio? Solutio. Hic pondero quod, sicut in foro contentioso causa peroratur, sic per campiones in iudicio duellari, et sic infero quod, sicut in iudicio contentioso fieri debet aequa advocatorum distributio, ut l. providendum, C. De postul., sic, ubi hinc inde fit campionum concessio, debet fieri ipsorum aequa distributio. In principalibus autem duellantibus non est ponderanda aequalitas, vel inequalitas, cum causam propriam propriis viribus corporis sponte ad exitum perducant, und Paride del Pozzo (Anm.9), lib. V, c. IIII, unpag.: E da sapere anchora che quando la battaglia personale se fa per campioni se debbeno elegere per il iudice equale de fortezza; perche se luno trouasse vn fortissimo armigero per suo campione tale che nela sua prouincia non se trouasse simile a quello de fortezza, alhora se deueriano distribuire li campioni de vna equalita, secondo la constitutione predicta, et la lege longobarda; pero questo non se obserua de consuetudine; ma se debbe notare che li campioni debbeno esser de eta magiore de vinticinque anni.

$71 \mathrm{Vgl}$. Cavina (Anm. 8), S. 29: „[...] ma le norme sui campioni tradivano effettivamente la sfiducia verso la loro onestà e rispecchiavano scandali ed abusi.“

72 Statuten von Mailand (1216) (zit. nach Merendoni [Anm. 48], S. 19): Campiones vero per se iurant quod per vim herbarum vel verborum vel alicuius maleficii ad pugnandum non veniunt et amplius quod bona fide pugnabunt. Vgl. Edictus Rothari (643), c. 368 (Edictus ceteraeque Langobardorum Leges. Hrsg. v. Friedrich Blume [MGH Fontes iuris]. Hannover 1869, S. 69): Nullus camphio praesumat, quando ad pugnando contra alium uadit, herbas quod ad maleficias pertenit, super se habere, nec alias tales similes res, nisi tantum arma sua, quae conuenit. Et si suspicio fuerit, quod eas occulte habeat, inquiratur ad iudicem, et si inuenta super eum fuerit, euellatur et iactentur. Constitutiones regni Sicilae Friedrichs II. (1231), II.38 (Stürner [Anm. 62], S. 345f.): Presenti lege decernimus, ut campiones amodo postquam circulum pugnatorium fuerint, prout est moris, ingressi, corporalia subeant sacramenta, quod iuxta probabilem credulitatem eorum credunt dominos, pro quibus pugnam intraverint, veritatem fovere et non per calumpniam seu per astum ad accusationem propositam vel ad defensionem adhibitam processisse, et quod cum omni virtute et potentia, studio et vigore partes, pro quibus pugnaverint, adiuvabunt. Pugilibus etiam expressius inhibemus, quod se non debeant invicem affidare, quod manibus et dentibus et modis, quibuslibet poterit, alter alterum non offendat, immo unus ad confusionem alterius ex toto posse conetur. Siehe dazu auch Paride del Pozzo (Anm.9), lib. V, c. VI, unpag.: Ciascuno Cavaliero debbe sapere si como deueno li campioni nel intrare dela liza iurare che secondo la loro 
Trägheit oder der absichtlichen Fehlleistung drohte ihm gemäß den Konstitutionen Friedrichs II. eine schwere Bestrafung als überführter Meineidiger. ${ }^{73}$ Dass die professionellen campiones in den Augen der Auftraggeber tendenziell im Verdacht standen, das eigene Überleben dem letzten Einsatz für eine fremde Rechtssache vorzuziehen, stellt ein strukturelles Problem der Kampfstellvertretung dar. ${ }^{74}$ Die eigentlich positiv gemeinte Einlassung Hugos von Trimberg, der in seinem um 1300 verfassten Lehrgedicht ,Der Renner‘ der todesmutigen ritterlichen Turniermanie das weise, das eigene Leben nicht fahrlässig gefährdende Kampfgebaren der Kämpen entgegenstellte, ${ }^{75}$ konnte in der Arena des gerichtlichen Zweikampfs schnell in Betrugsvorwürfe umschlagen. Die Grenzlinie zwischen einem gerade noch zulässigen Kampfeinsatz und einer manipulativen Indifferenz war in der Praxis überaus schwer $\mathrm{zu}$ interpretieren. Nicht von ungefähr war in den Konstitutionen Friedrichs II. dem jeweiligen Aufsichtsorgan anheimgestellt, zur Bewertung des Kampfgebarens Stellungnahmen von weiteren Beobachtern einzuholen. ${ }^{76}$ Daneben galt es auch, etwaigen vorherigen Absprachen zwischen Parteien und Kampfstellvertretern in betrügerischer Absicht vorzubeugen: Dies geschah mitunter mittels eines Losverfahrens, so dass

credenza gli patroni de la querela perliquali deliberassero combattere hanno iusta cagione, et de non accusare luno l'altro per fraude, ne per malitia, et che con ogni virtu, et possanza defenderanno ciascuno lo honore del suo signore. Iurano anchora li campioni che non habbiano intelligentia fra loro de luno non offendere l'altro, et de fare tutto il devere con tutta la loro virilita se sforzaranno menare le mane per essere l'uno de l'altro vincitore senza fraude de fingimento alcuno; et per questo descriue lo Imperatore Federico il quale anchora misser Baldo de Perugia referisse. Vgl. dazu Nottarp (Anm. 10), S. 303, und Patetta (Anm. 7), S. 434, Anm. 5.

73 Constitutiones regni Siciliae Friedrichs II. (1231), II.39 (Stürner [Anm. 62], S. 346f.): [...] si is, qui pugne pro tempore prefuerit, videat cum aliorum consilio, qui tunc temporis inveniuntur esse presentes, quod campio in pugnando fraudem adhibeat aut segnitiem manifestam vel quod melius potuerit se defendere nec tam cito in recredentis vocem prorumpere debuisset: si quidem is, pro quo pugnat, accusatus extiterit, cum, si pugne succumbat, mori debeat utpote reus criminis maiestatis vel de homicidio absconso convictus, campio similiter periculum mortis incurrat. Ceterum si is, pro quo pugnat, accuset, quia forte dolorem iustum prosequitur pater vel forte mater aut filius de morte suorum, quia, si succumbat in pugna, mori non debet, cum nec ad pugnam fuisset admissus, nisi quia ipsum iusti doloris impetus et indiciorum precendentium probatio amiserunt, campio tantum manum amittat quam exigente legitima pena periurii quilibet alius scienter periurus amittit. Videbatur enim impium in casu presenti capitali supplicio subicere campionem, cum is, cuius causam principaliter agit, per casum suum periculo capitis non succumbat.

74 Galbraith (Anm. 36), S. 289: „[...] marked disinclination at all stages of these witness-champions - like the Italian condottieri - to proceed to extremes“.

75 Hugo von Trimberg, Der Renner. Hrsg. v. Gustav Ehrismann. Bd. 3. Tübingen 1909, V. 11641-11644: Der kempfe was wîser denne die degen,/Die man siht justierens pflegen/Und maniger ander offenheit,/Diu ir leben veile treit. Vgl. dazu Neumann (Anm. 3), S. 185.

76 Siehe Zitat Anm. 73. 
die Zuordnung der Kämpen zu den beiden Streitparteien erst nach dem Zweikampf offengelegt wurde. ${ }^{77}$ Besonders ausführlich berichten die Statuten von Viterbo (1251-1252) über diese Prozedur: Die Namen der Kämpen sollten auf zwei brevicelli notiert und mit dem Siegel der Kommune verschlossen werden, woraufhin jeweils einem Vertreter der Parteien ein solches Schriftstück übergeben wird. Nach Beendigung des Zweikampfs sollten diese brevicelli an den Podestà zurückgegeben, auf einen etwaigen Siegelbruch hin untersucht und dann geöffnet werden, so dass es ,allen Leuten klar vor Augen trete, wer den vorgenannten Kampf gewonnen und verloren hat". ${ }^{78}$ Noch am Ende des 15. Jahrhunderts warnte Paride del Pozzo in seinem Traktat ,De duello“ eindringlich vor der corruptione der Kämpen per dinari, denn der Zweikampf diene doch eigentlich der Wahrheitsfindung über das Medium der Waffengewalt. Einen Lohnkämpfer mit finanziellen Leistungen dahingehend $\mathrm{zu}$ manipulieren, dass er auf dem Kampfplatz nicht den vollen Einsatz bietet, ziehe eine vitoria turpissima, einen schändlichen Sieg, nach sich und unterstehe schwersten Strafen. ${ }^{79}$ Dabei erin-

77 Pertile (Anm. 33), S. 343. Vgl die Statuten von Bologna (1250), lib. II, rubr. V (Frati [Anm. 65], S. 259): [...] et postquam pugiles electi fuerint quod nesiatur cuius sit pugil sed sint duo brevia in quibus scripta sint nomina partium, et quidam puer virgo debeat ponere breve unum in quollibet cubone, et suatur in dictis cubonibus et uno ex pugillis victo desuantur cubones in presentia partium et tunc sietur que pars obtinuit.

78 Statuten von Viterbo (1251-1252) (Federici [Anm. 53], S. 164): [...] et postea faciat fieri duos brevicellos; in uno contineatur camphio albi coloris, et in alio camphio coloris rubei, et claudantur sub cera et signentur sigillo Comunis. et sic, post mandatum potestatis, faciat accipere quamlibet partem unum illorum, et precipiat sub banno .c. librarum cuilibet partium aut procuratoribus eius vel eorum, ut illud in manu teneat donec pugna fiat, et nullo modo aperiatur, ut sciri non possit quis sit camphio unius partis et quis alterius usque ad finem pugne. verumtamen Curia interim bona fide procuret, ut fiat compositio inter partes. si autem compositio fieri non poterit, finita pugna, precipiat potestas utrique parti ut deferant breves signatos ad ipsum, et consideret ne dictum sigillum est fractum. et accepto brevi de manu unius partis, aperiat palam dictum brevem coram partibus et aliis, ut sciatur quis est camphio illius partis, et eodem modo fiat de alio brevi, ut manifeste sciant gentes omnes, quis obtinuerit et quis amiserit pugnam predictam.

79 Paride del Pozzo (Anm.9), lib. V, c. IX, unpag.: Como non e licito corrompere il campione. Nela constitutione de Federico se descrive che sel campione fosse dal nimico corrupto per farse vincere, benche sia licito nela battaglia de tutta oltranza con ogni fraude superare lo aduersario,; non faria pero in tal caso vincitore; perche non merita victoria secondo la lege ciuile chi vince con corruptione de premio alcuno; perche tale battaglia fo inuenta per iudicio de trovare la verita per forza d'arme, chel contrario suo e lo corrompere per dinari, como quello ilquale vince la sententia corrompendo il iudice, e li testimonii non e legitimo vincitore; quantunche in battaglia de tutta oltranza sia licito usare ogni astutia, et ogni fraude per vincere, non pero e permesso de vsare falsita de corrumpere il campione che non faccia il deuere in iudicio de battaglia; perche la victoria che se obtenesse saria turpissima; perche li antiqui Imperatori li virtuosi pugnatori coronauano, et denegauano a quelli che procurauano la victoria corrumpendo li aduersarii per conseguire lo honore del triumpho; benche sia licito, como piu volte et dicto de sopra in battaglia de tutta 
nert Paride del Pozzos Mahnung, nur ein Zweikampf ohne corruptione garantiere einen ehrenvollen Sieg, an die zeitgleich gültigen Regeln des fair fighting, die gerade auch städtische Gerichte diesseits und jenseits der Alpen beschäftigten. Wie Ann Tlusty in ihrer jüngst erschienenen Studie zur städtischen Gewalt- und Waffenkultur zeigen konnte, hatte das Prinzip der coequatio in Bezug auf Kampfkompetenz sowie Bewaffnung und der Verzicht auf heimliche Manipulationen als Legitimierungscodes städtischer Ehrenhändel einen festen Platz. ${ }^{80}$ Indem Paride del Pozzo im Sinne des honore dela battaglia eine klare Rollenerwartung an die Parteien und deren Kämpen formulierte, rekurrierte er auf Regeln des agonalen fair play, die gerade auch für das Gebaren der professionellen Kampfstellvertreter als Entscheidungsakteure über Recht und Unrecht gelten sollten.

\section{Institutionalisierungsfaktor: Qualifikation}

Der dritte Institutionalisierungsfaktor besteht in den Qualifikationsvoraussetzungen, die mit dem Kämpendienst verbunden waren. So galt etwa in vielen italienischen Statuten das Indigenitätsprinzip: „Es dürfen nur Kämpen akzeptiert werden, die aus der Stadt und Diözese Vercelli stammen“, heißt es etwa in den dortigen Statuten von 1241, und in Padua soll der Podestà ebenfalls nur Kämpen aus Padua und dem Paduaner contado zulassen. ${ }^{81}$ Ähnliche Bestim-

oltranza per leuare la potentia del inimico vsare ogni fraude per saluatione dela vita, se intende con propria astutia de virtu militare, pero sara piu estimato quello che vince per virtu de battaglia con la strenuita dela persona, che quello con fraude, et inganni senza gagliarda, et valorosita restano vincitori benche superasseno possenti Caualieri. Si che quello che corrumpe il campione non merita lo honore dela battaglia, et non po dire essere stato vincitore con arme, ne con spata; solo per corruptione la quale e molto da valorosi Caualieri condennata; perche e specie de grauissimi tradimenti, et da deuerse la victoria denegare, doue se debbe per virtu d'arme acquistare, et superare lo nimico per trovare la verita. Onde vno Philosopho dice che doue intervene corruptione de dinari non po essere cosa laudabile ne virtuosa, in questo iudicio de arme doue non e permesso corruptione alcuna se debbe vincere con la spata, et con la propria virtu de l'animo; et per questo non sa dara lo honore a quello che vince corrumpendo il campione; perche la corruptione e simile del delicto che merita gravissima pena; et per questo non se da premio, ne honore a quello che iustamente merita essere punito.

80 Tlusty (Anm. 22), S. 95-102.

81 Statuten von Vercelli (1241), c. 88 (Adriani [Anm. 50], S. 76): Non accipiatur campio nisi de Vercellis et de episcopatu Vercell.; Statuten von Padua (1236), c. XXX (Gloria [Anm. 48], S. 205): Campiones non admittat potestas nisi de Padua et paduano districtu ad pugnam faciendam [...]. Vgl. dazu auch Pertile (Anm. 33), S. 341, und Patetta (Anm. 7), S. 429. 
mungen finden sich auch in den Statuten von Bologna (1250) und Novara (1281), während die Parmeser Statuten von 1255 fordern, dass die Kämpen und ihre Angehörigen seit mindestens drei Jahren ununterbrochen ortsansässig sein mussten. ${ }^{82}$ Mit diesem Indigenitätsprinzip sollte verhindert werden, dass der Kämpendienst, wie etwa auch im England des 13. Jahrhunderts zuweilen belegt, von fahrenden Fremden verrichtet wurde, ${ }^{83}$ deren Ruf und Kompetenz von den Aufsichtsorganen der gerichtlichen Zweikampfs nur schwer einzuschätzen war. Im Sinne der Verfahrenskontrolle erschien es angeraten, auf einheimische Kämpen zu setzen; ${ }^{84}$ in der Konsequenz sind etwa in Padua ganze Kämpendynastien festzustellen, wie etwa die reiche Bürgerfamilie Cavacio, die aus Vicenza stammenden Bravi oder die aus dem Paduaner Umland eingewanderten Dal Rio. ${ }^{85}$

Eng mit dem Indigenitätsprinzip verbunden ist auch die Qualifikationsvoraussetzung des guten Leumundes, wenn etwa die Parmeser Statuten von 1255

82 Statuten von Bologna (1250), lib. II, rubr. V (Frati [Anm. 65], S. 259): [...] et debeat fieri per homines nostre civitatis et districtus, et non per alios [...]; Statuten von Novara (1281) (zit. nach Pertile [Anm. 33], S. 341, Anm. 34): Et sint campiones de civitate vel iurisdic tione Novarie; Statuten von Parma (1255) (zit. nach Merendoni [Anm. 48], S. 21): [...] et campiones esse debeant de civitate et episcopatu Parmae per triennum continue [et ejus familie] sine fraude [...]. Vgl. dazu Nottarp (Anm. 10), S. 302.

83 Bartlett (Anm. 22), S. 112: „Several of the champions recorded in thirteenth-century England were from outside the realm, like Duncan the Scot, who was enlisted to fight duels on the writ of right in Dorset in 1229 and Middlesex in 1230“.

84 Vgl. Nottarp (Anm. 10), S. 302: „[...] [M]an wollte die Gewähr haben, daß der Kampf ehrlich und recht ausgefochten werde, dazu konnte man keine unbekannten Leute gebrauchen [...]“.

85 Ludovico Antonio Muratori, Dissertatio Trigesimanona. De duello ejusque origine ac usu. In: Ders., Antiquitates Italicae Medii Aevi sive Dissertationes. Bd. 3. Mailand 1740, S. 633-660, hier S. 636f.: Diu etiam Patavii perdurasse hunc morem testatur Anonymus Auctor, cujus Tractatum MStum (sic!) de Generatione aliquorum civium urbis Paduae possideo. Ibi haec leguntur: Cavacii fuerint divites populares, tempore Ezerini de Romano, in Vico S. Urbani qui ante existerant Campiones ballorum. Talis enim erat antiquorum consuetudo. Si duo nobiles aut potentes homines inter se homicidium comisissent, utraque pars inveniebat sibi unum Campionem pretio: et ordinata die hi duo Campiones intra stangatum, quod iuxta portam Baxanelli erat ordinatum, ponebantur, et claudebantur armati clypeis, baculis et Maschariis de ligno [...]; Merendoni (Anm.48), S. 34, Anm. 3: „Alcune notizie date per l'anno 1404 da un anonimo padovano, ma riferite però al passato sui campioni, informano di due famiglie nelle quali dei loro membri esercitavano tale professione. In una di queste furono prima campioni e poi scriminatori (nella notizia è stato sicuramente un errore lo scriverli in una successione invertita), confermando così una precisa testimonianza a riduardo. ,Bravi. Oriundi da Vicenza da gente non molto nobile. Esercitavano in Padova per molto tempo l'ufficio dei campioni die litiganti e perciò anch'essi ebbero il nome di campioni'. ,Rio, detti anche dal Rio, Buzzaniti, Scrimia. Furono originari dal Rio del padovano, nati da gente non molto nobile. Esercitavano in Padova l'arte di scrimiatori e di campioni'“. 
von den Kämpen verlangen, dass sie sich sine fraude drei Jahre lang in der Stadt aufgehalten haben mussten. ${ }^{86}$ Eine solche Bindung des Kämpendienstes an den guten Ruf und die Unbescholtenheit des Kandidaten liest sich auf den ersten Blick überraschend, denn in der gelehrten Theologie wurde die martialische Tätigkeit der Kämpen im Rahmen des seit 1215 gemeinrechtlich verbotenen Zweikampfverfahrens mehrheitlich als Todsünde gebrandmarkt und damit einer sozialen und rechtlichen Abwertung dieses Berufsstandes Vorschub geleistet. ${ }^{87}$ Allerdings ist in den großen italienischen Zweikampftraktaten des 13. bis 15. Jahrhunderts im Zuge der römischrechtlichen Funktionsbestimmung des Kämpendienstes eine diametral entgegengesetzte Position zu besichtigen. Unter der Rubrik Quis possit esse campio, „wer kann Kämpe sein“, stellt etwa Roffredo Beneventano zunächst fest, dass jeder zum Kämpen zugelassen werden könne, bei dem keine Ausschlussgründe vorlägen, um dann fortzufahren: Infamis etiam campio non esse potest, „eine unehrliche Person kann kein Kämpe sein“. ${ }^{8}$ Würde ein infamer Kämpe zum Kampf zugelassen, argumentiert der Autor weiter, wäre eine etwaige Niederlage wohl eher einem Verbrechen des Kämpen als einem Delikt des Klägers oder Beklagten zuzuschreiben. ${ }^{89}$ Mit anderen Worten: Die Stellvertretungsfunktion wäre durch einen campio infamis von vornherein gestört, der Ausgang des gerichtlichen Zweikampfs depraviert und als Mittel der Wahrheitsfindung nutzlos. „Aber wenn die Kämpen, wie heutzutage üblich, nur gegen Entlohnung kämpfen, sind sie dann nicht automatisch unehrlich?“, fragte Roffredo Beneventano weiter, nicht ohne sogleich zu erwidern: Auch der Anwalt sei ja nicht deswegen unehrlich, weil er seine Dienste gegen Geld anbietet. ${ }^{90}$ Auch wenn, namentlich durch Andreas Bonellus de Barulo, in der zweiten

86 Siehe das Zitat Anm. 82. Vgl. dazu Nottarp (Anm. 10), S. 302, und Neumann (Anm. 3), S. 60, Anm. 246.

87 Vgl. Neumann (Anm. 3), S. 185; Cavina (Anm. 8), S. $28 \mathrm{f}$.

88 Roffredo Beneventano (Anm.7), c. V, S. 488f.: V. Quis possit esse campio. Campio de iure longobardo admittitur omnis ille qui non repellitur; sic et in postulando iure romano, ad quod omnes admittuntur nisi repellantur, ut ff. de postul. l. I. Concordant enim campio et advocatus, unde sicut per advocatum causa examinata deciditur, ut C. de advo. di. iu. l. „advocati”, ita et per campionem. Fur autem campio esse non potest, ut in lomb. qualiter quis se de. de. l. „ut campionem"; et est ratio quia praesumitur quod si in pugna succumberet, potius succumberet propter delictum suum, quam propter delictum actoris vel accusati. Infamis etiam campio esse non potest, et omnis fur est infamis, ut ff. de furtis, l. "non potest” et ita repellitur quicumque est om criminali peccato ratione predicta.

89 Siehe das Zitat in der vorigen Anm.

90 Ebd., S. 489: Sed cum hodie campiones non soleant pugnare, nisi locata opera sua, num eo ipso sunt infames? Ita videtur, ut ff. de his qui no. infa. l. II, in fi. et de postul. l. I, circa medium; at ille leges locuntur de his qui ludibrium sui corporis faciebant, puta, prodeundo in scenam, vel pugnando cum bestiis feris. At campio, licet locet operas suas, non est infamis, ut ff. de his qui 
Hälfte des 13. Jahrhunderts auch gegenteilige Stimmen in der juristischen Kommentarliteratur laut wurden, ${ }^{91}$ belegt doch die ausdrückliche, funktional begründete Distanzierung des Kämpen aus dem Kreis der unehrlichen Personen einmal mehr den Institutionalisierungsgrad des officium campionatus ${ }^{92}$ gerade in den Städten Nord- und Mittelitaliens; hier wurde der Figur des Kämpen eine Wertschätzung entgegenbracht, die gerade im europäischen Vergleich hervorsticht. ${ }^{93}$

\section{Fazit}

Während in deutschen Städten des Spätmittelalters das Bild des fahrenden, rechtlosen Kämpen durch eine Festanstellung mit einer stabilen monatlichen

no. infa. l. „atletas”; sic nec advocatus est infamis, qui hodie locat operas suas, licet secundum leges sit infamis, ut C. de postul. l. „quisquis”; sed illa de advocatis percipientibus salarium de publico loquitur. Vgl. Giovanni da Legnano (Anm. 6), lib. VI, pars 7, c. clxxxii, S. 190: An quilibet admittatur pro campione? Quarto quaero, an quilibet admittatur pro campione? Solutio. Vt dictum est, hic aequiparatur campio advocato, sicut igitur quilibet admittitur ad postulandum, nisi sit prohibitus, ut l. i, ff. De postul.; sic quilibet admittitur ad officium campionatus, nisi repellatur a iure. Repellitur autem fur, ut in Lombarda, Qualiter quis se defendat, l. si ut campionem. Et est ratio, quia infamis, ff. De furt., l. non potest; et si succumbit, praesumitur ratione proprii delicti succumbere, sic et alii criminosi gravibus criminibus irretiti, ratione praedicta; Paride del Pozzo, Duello, lib. V, c. V, unpag.: Capitolo V. Como persone infame non se possono dare per campioni. E da notare anchora che li campioni non deueranno essere persone infame, perche sono simili a li doctori iuristi che sone aduocati nele cause civile che defensano; et in caso che vno fosse ladro manifesto non potria essere campione, ne homini de mala conditione liquali verisimilmente sempre in battaglia sariano perditori piu per cagione de loro delicti, che per diffecto de mala querela del signore a instantia delquale combatesseno. Anchora quello il quale havesse commesso delicto perloquale non potesse nela presentia del suo principe comparere non potria essere campione, ne anchora homini che per dinari havesseno commesso homicidio como sono assassini, ruffiani publici, et altre simile generatione de vilissimi beccarini, ne von apostato, cioe religioso fugito del suo monasterio; et questo se troua secondo la lege longobarda, et civile; et secondo Andrea de ysernia, excepto se pugnassero con persone infame simile de loro, perche alhora da nissuno se potria la battaglia refutare.

91 Cavina (Anm. 8), S. 28f., mit Verweis auf Andreas Bonellus de Barulo (Andrea da Barletta, 2. Hälfte 13. Jh.), Commentaria in tres libros codicis. Venedig 1605 (ND Bologna 1975), S. 190: [...] sed isti pugiles, qui ad pugnandum precio assumuntur, infames sunt, vt ff. de his, qui not infam l.2.\$.est. Item testes debent scire ueritatem, vt supra de testib.l. testium, quam constat pugiles, conductos precio, ignorare [...].

92 Siehe das Zitat in Anm. 85.

93 Vgl. Lea (Anm. 2), S. 168: „The Italians, however, took a more sensible and practical view of the matter. Accepting as a necessity the existence of champions as a class, they were disposed rather to elevate than to degrade the profession.“ 
Entlohnung relativiert wird, geht aus der nord- und mittelitalienischen Statutenüberlieferung ein ganzes Bündel an Faktoren hervor, die den Kämpendienst fest im Verfahrensgang des gerichtlichen Zweikampfs verankern und zugleich die Kontrolle städtischer Amtsträger festschreiben. Das officium campionatus erscheint in diesem Kontext als hinreichend institutionalisiertes, „geregeltes Gewerbe“, ${ }^{44}$ mit einer auftragsgebundenen Entlohnung nach festen Tarifen, mit einer ergebnisoffenen Zweikampfbesetzung im Sinne der coequatio, schließlich mit Auflagen im Hinblick auf die Ortsstabilität und persönliche Integrität, die Betrugs- und Manipulationsversuchen vorbeugen und der schwierigen Leumundskontrolle bei fahrenden Kämpen abhelfen sollten. Auf dieser Grundlage gelang es gerade der italienischen Duelltraktatistik des 13. bis 15. Jahrhunderts, im Rahmen der allgemeinen kasuistischen Verrechtlichung des gerichtlichen Zweikampfs auch den campio in einen advocatus und damit mithin einen Akteur der Rechtspflege umzudefinieren. Indem dem Kämpen eine letztlich entscheidende Rolle bei der rechtlichen Wahrheitsfindung zugeschrieben wurde, konnte nur ein unbescholtener Kämpe seine Funktion im Rahmen des gerichtlichen Zweikampfes ausüben - eine Qualifikationsvoraussetzung, die mit der vermeintlichen Marginalität der Kampfstellvertreter nicht zu vereinbaren ist. Anders als im Falle des kämpflichen Austrags der kollidierenden Rechtspositionen durch die Streitparteien selbst war allerdings die sekundäre Repräsentationsfunktion des Kämpen stets von Fragezeichen umgeben, denn seine Professionalität transzendierte die Wahrheitskonstellation des einzelnen Rechtsfalls zugunsten einer rein finanziellen Motivation. Der durchaus naheliegende Verdacht, Lohnkämpfer könnten in Manipulationen oder Absprachen verstrickt sein oder ihr eigenes Überleben einer engagierten Kampfstellvertretung vorziehen, durchzieht jedenfalls die italienischen Statutensammlungen, die nicht von ungefähr die Rolle des Kämpen in ein normatives Korsett einspannten. Gleichzeitig in ihrer Funktion unverzichtbar und latent verdächtig, gleichzeitig sine fraude und rechtelos, spiegelt sich in der Figur des Kämpen eine grundsätzliche Mehrdeutigkeit zwischen Marginalität und Rechtspflege, wie sie nach Sarah NEUMANN dem gerichtlichen Zweikampf auch generell zukommt. ${ }^{95}$

Langfristig sollte dem Kämpendienst im Rahmen eines zum Ehrenduell gewandelten Zweikampfverfahrens ${ }^{96}$ kein Platz mehr bleiben: „Wir sehen, dass

94 Nottarp (Anm. 10), S. 302. Vgl. Neumann (Anm. 3), S. 60, Anm. 246.

95 Vgl. Neumann (Anm. 3), S. 27.

96 Zur Praxis des gerichtlichen Ehrenduells siehe Cavina (Anm. 8), S.41-102; ders., (Anm. 7), bes. S. 59-88. Zum Phänomen der Ehre allgemein siehe Klaus Schreiner u. Gerd Schwerhoff, Verletzte Ehre. Überlegungen zu einem Forschungskonzept. In: Dies. (Hgg.), Verletzte Ehre. Ehrkonflikte in Gesellschaften des Mittelalters und der Frühen Neuzeit (Norm und Struktur. 
die Gewohnheit, Kämpen antreten zu lassen, von niemandem mehr akzeptiert wird und wie eine verderbliche Sache außer Gebrauch gekommen ist“, schrieb Dario Attendoli 1560 in seinem Traktat ,Il duello', denn es gebe „heutzutage niemanden mehr, der sein Heil und seine Ehre in die Hände eines Anderen geben will." ${ }^{97}$ Wo Fragen der persönlichen Ehre auf dem Spiel standen, war das Prinzip der Kampfstellvertretung obsolet und die stets mit Argusaugen beobachteten Kämpen arbeitslos geworden. Die eigene Ehre als nach Hegel „das schlechthin Verletzliche“98 konnte nur am eigenen Leib und nicht durch einen Anderen wiedererlangt oder verloren werden.

Studien zum sozialen Wandel in Mittelalter und Früher Neuzeit 5). Köln, Weimar, Wien 1995, S. 1-28.

97 Dario Attendoli, Il duello. Venedig 1562, Bl.51v-52r: Ma ueggiamo ch'ella non è d'alcuno accettata in effetto, \& che come corrutella è andata in abuso. Imperoche nissuno al dì d'hoggi si ritrova che quando, o la dignità sua nel richiede, o che lo impedimento proprio gli vieta di potere combattere che voglia confidere nell'altrui mano la sua salute \& il suo honore [...]. [...] aggiungo quest'altra che essendo il Duello permesso hoggidì solo per causa d'honore, l'honore è annesso alla persona come una attion personale \& dalla persona dipende \& dalla virtù, \& dal valore dell'huomo, onde che se non è vinta la istessa persona non si puo leuargli l'honore come cosa individua, è inseperabil da quella cosi adunque è impossibile ch'uno sia uinto \& ch'habbia perso l'honore, che per se medesimo combattuto non habbia et con la propria persona [...].

98 Georg Wilhelm Friedrich Hegel, Ästhetik. Nach der zweiten Ausgabe Heinrich Gustav Hothos (1842) redigiert und mit einem ausführlichen Register versehen von Friedrich Bassenge. Bd.1. Weimar 1965, S. 535: „Indem nun die Ehre nicht nur ein Scheinen in mir selber ist, sondern auch in der Vorstellung und Anerkennung der anderen sein muß, welche wiederum ihrerseits die gleiche Anerkennung ihrer Ehre fordern dürfen, so ist die Ehre das schlechthin Verletzliche.“ 